\title{
1 Assessing the effects of spatial discretization on large-scale flow model performance
}

\section{2 and prediction uncertainty}

3 Wildemeersch, $\mathrm{S}^{\mathrm{a}, *}$, Goderniaux $\mathrm{P} .{ }^{\mathrm{b}}$, Orban $\mathrm{Ph} .{ }^{a}$, , Brouyère $\mathrm{S} .{ }^{a}$, Dassargues $\mathrm{A} .{ }^{\mathrm{a}}$

4 a University of Liege, ArGEnCo, GEO3, Hydrogeology and Environmental Geology, Aquapôle, B52/3 Sart-

5 Tilman, 4000 Liege, Belgium

$6{ }^{b}$ University of Mons, Faculty of Engineering, Fundamental and Applied Geology Department, Rue de

7 Houdain 9, 7000 Mons, Belgium

$8 *$ Corresponding author at: University of Liege, ArGEnCo, GEO ${ }^{3}$, Hydrogeology and Environmental

9 Geology, Aquapôle, B52/3 Sart-Tilman, 4000 Liege, Belgium. Tel.: +32 (0)43669553. Fax:

$10+32(0) 43669520$.

11 E-mail address: swildemeersch@ulg.ac.be (S. Wildemeersch)

\section{Abstract}

13 Large-scale physically-based and spatially-distributed models $\left(>100 \mathrm{~km}^{2}\right)$ constitute useful tools for

14 water management since they take explicitly into account the heterogeneity and the physical processes

15 occurring in the subsurface for predicting the evolution of discharge and hydraulic heads for several

16 predictive scenarios. However, such models are characterized by lengthy execution times. Therefore,

17 modelers often coarsen spatial discretization of large-scale physically-based and spatially-distributed

18 models for reducing the number of unknowns and the execution times. This study investigates the

19 influence of such a coarsening of model grid on model performance and prediction uncertainty. The

20 improvement of model performance obtained with an automatic calibration process is also investigated.

21 The results obtained show that coarsening spatial discretization mainly influences the simulation of

22 discharge due to a poor representation of surface water network and a smoothing of surface slopes that 
prevents from simulating properly surface water-groundwater interactions and runoff processes.

24 Parameter sensitivities are not significantly influenced by grid coarsening and calibration can compensate, to some extent, for model errors induced by grid coarsening. The results also show that coarsening spatial discretization mainly influences the uncertainty on discharge predictions. However,

27 model prediction uncertainties on discharge only increase significantly for very coarse spatial discretizations.

Keywords: spatial discretization; model performance; sensitivity analysis; automatic calibration; prediction uncertainty.

\section{$31 \quad 1$ Introduction}

32 Large-scale physically-based and spatially-distributed models $\left(>100 \mathrm{~km}^{2}\right)$ are increasingly used in water management for their unique capacity of gathering every piece of information obtained on a

34 hydrological system to simulate its quantitative and qualitative evolution for several predictive

35 scenarios. These models are intended to provide predictions on both the integrated response

36 (discharge) and the distributed response (hydraulic heads) of the catchment.

37 Physically-based and spatially-distributed models take explicitly into account the heterogeneity and the physical processes occurring in the surface and the subsurface. Therefore, they are expected to provide predictions with higher level of confidence than black-box models (e.g. Ebel and Loague, 2006; Li et al.; 2008; Goderniaux et al., 2009). Additionally, they are also used for improving the understanding of the physics of hydrological processes (e.g. Frei et al., 2009; Meyerhoff and Maxwell, 2011; Irvine et al.,

42 2012). However, physically-based and spatially-distributed models are characterized by lengthy

43 execution times, especially for integrated surface and subsurface transient flow simulations at large44 scale. Consequently, choices and simplifications are made for obtaining tractable execution times. The 
most common simplification consists in coarsening the spatial discretization for reducing the number of

46 unknowns of the problem and the execution time. The effects of such a coarsening of model grid are

47 worthy being studied since they can limit the accuracy of model results and increase model prediction uncertainties.

A series of studies have already been performed on the effects of spatial discretization on physicallybased and spatially-distributed model performance. Refsgaard (1997) calibrated and validated a 3D model with a 500 m grid i.e. with a constant element size of 500 m (no refinement) for the Karup catchment in Denmark $\left(440 \mathrm{~km}^{2}\right)$. Three other models with $1000 \mathrm{~m}, 2000 \mathrm{~m}$, and $4000 \mathrm{~m}$ grids were then generated using the same parameter values than those obtained by calibration for the initial model

54 (no recalibration, no upscaling). The models were compared in terms of both discharge and hydraulic heads. The results from this study indicated that runoff was poorly simulated by the models coarser than $1000 \mathrm{~m}$ due to a poor representation of the surface water network which prevents from simulating

57 properly surface water-groundwater interaction. However, the author suggested that a significant recalibration of models with a coarse grid could improve their performance. This is supported by the study of Vàzquez et al. (2002). They calibrated a 3D model with a $600 \mathrm{~m}$ grid i.e. with a constant element size of $600 \mathrm{~m}$ (no refinement) for the Gete catchment in Belgium $\left(586 \mathrm{~km}^{2}\right)$. They also generated a second model with a finer grid $(300 \mathrm{~m})$ and a third model with a coarser grid (1200 m) using the same parameters than those obtained by calibration for the initial model (no recalibration, no upscaling). These $300 \mathrm{~m}$ and $1200 \mathrm{~m}$ grid models were then recalibrated individually using a trial-and-error 64 calibration process. As for the study of Refsgaard (1997), the models were compared in terms of both discharge and hydraulic heads. Although, in general, model results remained worse for the $1200 \mathrm{~m}$ grid model than for the $300 \mathrm{~m}$ and the $600 \mathrm{~m}$ grid models, this study proved that a recalibration is required

67 for obtaining effective parameter values and improving model performance when the grid resolution is 68 changed. Sciuto and Diekkrüger (2010) developed a 3D model with a $25 \mathrm{~m}$ grid refined in the river zone 
for the Wüstebach catchment in Germany $\left(0.27 \mathrm{~km}^{2}\right)$. They also developed a second model with a $100 \mathrm{~m}$

70 grid using the mean averaging method for upscaling parameter values and a third model with the same

71 model grid than the initial model and the same soil configuration than the second model. They

72 compared the results obtained in terms of discharge and spatial pattern of soil moisture. The influence

73 of upscaling was investigated by comparing the first and the second models and the effects of spatial

74 discretization were studied by comparing the second and the third models. They showed that a coarse

75 grid leads to higher discharge and less actual evapotranspiration than a fine grid due to the smoothing

76 of soil surface which induces a loss of topographic information. They also showed that the upscaling

77 technique they selected was efficient for simulating discharge and spatial pattern of soil moisture. They

78 suggested that the nonlinear relationship between soil moisture and evapotranspiration could explain

79 the deterioration of model results when the grid is coarsened without parameter upscaling. However,

80 none of their models were calibrated. Downer and Ogden (2004) performed a spatial convergence study

81 for the Hortonian Godwin Creek Experimental catchment $\left(21.2 \mathrm{~km}^{2}\right)$ and the non-Hortonian Muddy

82 Brook catchment $\left(3.64 \mathrm{~km}^{2}\right)$ in the US. They developed a series of 2D vadose zone model of increasing

83 vertical cell size for each of these catchments. The models were calibrated with an automated

84 calibration process using the shuffled complex evolution method. The calibrated models were compared

85 in terms of infiltration, runoff, and evapotranspiration fluxes to evaluate the appropriate vertical

86 discretization required for accurately solving the Richards' equation. The results from this study showed

87 that small vertical cell size (on the order of centimetres) is required in the unsaturated zone to

88 accurately simulate hydrological fluxes. However, providing that effective parameters obtained by

89 calibration are used, the results of this study also shows that it is possible to slightly increase vertical cell

90 size in the unsaturated zone without significantly deteriorating the simulation of hydrological fluxes.

91 These results about the vertical cell size required in the unsaturated zone for accurately solving the

92 Richards' equation are consistent with those obtained by Vogel and Ippisch (2008). 
93 All these studies provide valuable information on the effects of spatial discretization on model

94 performance. However, most of them neglect the calibration or use a simple trial-and-error calibration

95 process which is, by nature, subjective (Poeter and Hill, 1997). An automatic calibration process is

96 essential for properly evaluating the capacity of calibration to improve the performance of models with

97 a coarse grid. The present study includes such an automatic calibration process. Additionally, the

98 present study includes for the first time an evaluation of the influence of spatial discretization on model

99 prediction uncertainties by comparing the linear confidence intervals on predictions calculated for each

100 model.

101 The objective of the present study is to evaluate the effects of horizontal spatial discretization on

102 discharge and hydraulic heads simulated by a large-scale physically-based and spatially-distributed

103 model. This evaluation is performed using graphs of model fit and performance criteria. The

104 improvement of model performance obtained with an automatic calibration process is also investigated

105 and linear confidence intervals on predictions are calculated for each model. The results of this study

106 can help modelers defining the horizontal spatial discretization for their models by better perceiving its

107 influence on model performance and model prediction uncertainties.

\section{Methodology}

109 The effects of horizontal spatial discretization on model performance and model prediction

110 uncertainties are investigated using a synthetic catchment. The hydrological processes in this synthetic

111 catchment are simulated with HydroGeoSphere (Therrien et al., 2012). HydroGeoSphere is a fully-

112 integrated physically-based hydrological model capable of solving very complex problems such as

113 integrated flow in large-scale catchments (for example, see Goderniaux et al., 2009; 2011). Two-

114 dimensional surface water flow is represented using the two-dimensional diffusion-wave approximation

115 to the Saint-Venant equation. Three-dimensional subsurface water flow in both the saturated and the 
vadose zones is represented using the Richards' equation. The processes of interception and

117 evapotranspiration are modeled following the conceptualization of Kristensen and Jensen (1975). The

118 coupling of the surface to the subsurface is either performed with the common node approach

119 (continuity of hydraulic head between the two domains) or the dual node approach (exchange of water

120 between the two domains via a first-order exchange coefficient). A complete description of

121 HydroGeoSphere is available in Therrien et al. (2012). A short summary is provided in the paper of Li et

122 al. (2008) and in the software spotlight of Brunner and Simmons (2012a).

123 The choice of working with a synthetic catchment instead of a real catchment is motivated by the wish

124 of focusing only on the effects of horizontal spatial discretization on model performance. When working

125 with a synthetic catchment, the model geometry, the parameter values, and the boundary conditions

126 are exactly known. Furthermore, there is no measurement error on the observations produced.

127 Therefore, it is possible to test specific model features such as the influence of grid resolution on

128 discharge and hydraulic head simulation without unintentionally taking into account other sources of

129 errors related to a lack of knowledge of the hydrological system. The concept of synthetic catchment is

130 quite usual in hydrogeology (for example, see Poeter and McKenna, 1995; Hill et al., 1998; Schäfer et al.,

131 2004; Bauer et al., 2006, Beyer et al., 2006). The synthetic catchment generated for this study is complex

132 in that the flow system is fully-integrated and physically-based with consistent physical state

133 parameters. However, the synthetic catchment is simplified with respect to the heterogeneity of land

134 use and geology in reality. Yet, this study focuses on the effects of spatial discretization on model

135 performance and not on the influence of heterogeneity representation. The way grid size influences

136 model results would have been similar for a synthetic catchment with a higher level of heterogeneity,

137 provided that the heterogeneity is correctly represented. Therefore, despite this simplification, the

138 synthetic catchment is judged complex enough to serve the objective of this study. 
The methodology involves three main steps:

STEP 1 - Generation of the reference model/Generation of models with a coarse grid. A 5-year

141 simulation is run with the reference model for producing reference discharge and hydraulic head

142 observations. The reference model is characterized by a fine spatial discretization. The same 5-year

143 simulation is then run with models with a coarse grid using the same parameter values than those used

144 in the reference model (no calibration). These models with a coarse grid differ by their horizontal spatial

145 discretization (constant element size of $250 \mathrm{~m}, 500 \mathrm{~m}, 750 \mathrm{~m}$ model, or $1000 \mathrm{~m}$ ). The simulated values

146 of discharge and hydraulic head obtained with these models are saved for further graphical model fit

147 analysis and calculation of performance criteria.

148 STEP 2 - Calibration of models with a coarse grid. The models with a coarse grid are individually

149 calibrated using an automatic calibration process in order to evaluate how far parameter values can

150 compensate for errors induced by grid coarsening. However, prior to the calibration, a sensitivity

151 analysis is performed for evaluating the influence of horizontal spatial discretization on parameter

152 sensitivities.

153 The sensitivity of each parameter included in the calibration process is evaluated using the composite

154 scaled sensitivity $\operatorname{css}_{j}$ (Hill, 1992; Anderman et al., 1996; Hill et al., 1998; Hill and Tiedeman, 2007):

$155 \quad c s s_{j}=\left[\frac{\sum_{i=1}^{\text {nobs }}\left(d s s_{i j}\right)^{2}}{\text { nobs }_{b}}\right]^{1 / 2} j=1$, npar

156 with the dimensionless scaled sensitivities $d s s_{i j}$ calculated as

$157 d s s_{i j}=\left.\frac{\partial y_{i}^{g i m}}{\partial b_{j}}\right|_{b} \times\left|b_{j}\right| \times w_{i i}^{1 / 2} i=1$, nobs $j=1$, npar 
The composite scaled sensitivity measures the information provided by the entire set of observations for

159 the estimation of the single parameter $b_{j}$. Large values correspond to sensitive parameters for which the

160 observations provide a lot of information. According to Hill et al. (1998) and Hill and Tiedeman (2007),

161 parameters with composite scaled sensitivities less than 1 or less than 0.01 of the largest composite

162 scaled sensitivity are poorly sensitive. Consequently, they could produce problems during the calibration

163 or calibrated parameters with large confidence intervals.

164 The calibration is performed using PEST (Doherty, 2005) enhanced with the temporary parameter

165 immobilization strategy developed by Skahill and Doherty (2006). The iterative local optimization

166 method implemented in PEST allows calculating the set of parameter values that produces the smallest

167 value of an objective function measuring the discrepancies between observed values and their

168 simulated equivalent. The objective function implemented in PEST is the weighted least-squares

169 objective function $\left(L_{2}\right.$ norm):

170

$\Phi(\boldsymbol{b})=\sum_{i=1}^{n o b s} w_{i} \times\left[y_{i}^{o b s}-y_{i}^{\operatorname{sim}}(\boldsymbol{b})\right]^{2}=\sum_{i=1}^{n o b s} w_{i} \times r_{i}^{2}$

171 where nobs is the number of observations of any kind, $y_{i}^{o b s}$ is the $\mathrm{i}^{\text {th }}$ observed value, $y_{i}^{\operatorname{sim}}(\boldsymbol{b})$ is the

172 simulated equivalent to the $\mathrm{i}^{\text {th }}$ observed value calculated with the parameter values composing the

173 vector $\boldsymbol{b}, w_{i}$ is the weight for the $\mathrm{i}^{\text {th }}$ contribution to the objective function, $r_{i}$ is the $\mathrm{i}^{\text {th }}$ residual. However,

174 in presence of local minima in the objective function, this method based on local parameter sensitivities

175 does not always provide the set of parameter values corresponding to the global minimum. The use of

176 the temporary parameter immobilization strategy greatly reduces this eventuality. This strategy consists

177 in selectively withdrawing the most insensitive parameters from the estimation process when the

178 objective function improvement during a particular iteration is poor. This greatly heightens the capacity

179 of the estimation process to find the global minimum of the objective function. According to Doherty 
180 (2005), calibration using truncated singular value decomposition, gives similar results since this method

181 also has the capacity of withdrawing insensitive parameters from the estimation process. Global

182 optimization methods ensuring to find the global minimum of the objective function are not used in this

183 study because they require a huge number of model runs which induces execution times tens or

184 hundreds of times longer than the execution times required by local optimization methods (Hill and

185 Tiedeman, 2007). This precludes using these methods for integrated surface and subsurface transient

186 flow simulations at large-scale due to their long execution times.

187 The set of parameters included in both the sensitivity analysis and the automatic calibration is

188 composed of 32 parameters corresponding to the physical state parameters found in the equations

189 representing surface and subsurface flow processes in HydroGeoSphere. The parameters present in the 190 equations representing the interception and evapotranspiration processes are not included. The set of 191 observations is composed of 24 discharge rates and 288 hydraulic head observations ( 1 per month and 192 per observation point for 2 years) produced with the synthetic catchment. The simulated values of 193 discharge and hydraulic head obtained with these calibrated models are saved for further graphical 194 model fit analysis and calculation of performance criteria.

195 STEP 3 - Graphics of model fit, performance criteria, and linear confidence intervals on predictions.

196 Graphical model fit analysis and calculation of performance criteria are performed for each model to 197 evaluate qualitatively and quantitatively the effects of spatial discretization on model performance and 198 to evaluate the improvement of model performance obtained with calibration. Additionally, the 199 influence of horizontal spatial discretization on model prediction uncertainties is evaluated using linear 200 confidence intervals on predictions.

201 Graphics of model fit. Graphical model fit analysis is somewhat subjective. However, it is good practice 202 to perform such a visual inspection prior to use numerical criteria for an objective evaluation of model 
performance (Legates and McCabe, 1999; Hill and Tiedeman, 2007; Moriasi et al, 2007). Graphs

204 comparing observed and simulated values are the most widely used for evaluating model fit at a glance.

205 However, Hill and Tiedeman (2007) prefer using graphs such as weighted or unweighted simulated

206 values versus weighted residuals to facilitate the detection of model bias. If a model is unbiased, such

207 graphs exhibit weighted residuals evenly scattered about 0.0 for the entire range of values on the

208 horizontal axis. Weighted residuals $w r_{i}$ are calculated as (Hill and Tiedeman, 2007):

$209 \quad w r_{i}=w_{i}^{1 / 2} \times\left[y_{i}^{o b s}-y_{i}^{\operatorname{sim}}\right]=w_{i}^{1 / 2} \times r_{i}$

210 The purpose of weighting is essentially to emphasize the most accurate observations. This is achieved by

211 specifying weights that are proportional or, preferably, equal to the inverse of the observation error

212 variances (Hill and Tiedeman, 2007):

$213 \quad w_{i}=\frac{1}{\sigma_{i}^{2}}$

214 where $\sigma_{i}^{2}$ is the true error variance of the $i^{\text {th }}$ observation. Given these equations, in a graph of weighted

215 residuals versus unweighted simulated values, a cluster of negative weighted residuals indicate that

216 simulated values are systematically overestimated, and vice versa. Furthermore, with weights calculated

217 using a constant coefficient of variation, residuals are emphasized proportionally to their observed

218 value. Therefore, similar weighted residuals indicate similar relative errors. This way of emphasizing

219 residuals proportionally to their observed value is particularly useful for variables ranging over several

220 orders of magnitudes such as discharge.

221 Performance criteria. Performance criteria help quantifying model quality. They evaluate the level of

222 agreement between model and reality (Refsgaard and Henriksen, 2004). Typically, they depend on the

223 discrepancies between observed values and their simulated equivalent for a particular type of

224 observations (e.g. discharge or hydraulic heads). The performance criteria selected for this study are: 
$\left.\left.226 \quad N S E_{q}=1-\frac{\sum_{t=1}^{n t}\left(q_{t}^{\operatorname{sim}}-q_{t}^{o b s}\right)^{2}}{\sum_{t=1}^{n t}\left(q_{t}^{\operatorname{sim}}-\mu^{o b s}\right)^{2}} \in\right]-\infty ; 1\right]$

227 where $n t$ is the total number of timesteps, $q_{t}^{\text {sim }}$ is the simulated discharge at timestep $t, q_{t}^{\text {obs }}$ is the 228 observed discharge at timestep $t$, and $\mu^{o b s}$ is the mean of the observed values. If the simulated values 229 perfectly match the observed values, $N S E_{q}=1$. The lower the value of $N S E_{q}$, the poorer the model, 230 negative values indicating that the mean observed value $\mu^{o b s}$ gives a better description of the data than 231 the simulated values $q_{t}^{\text {sim }}$. Weglarczyk (1998) and Gupta et al. (2009) suggest decomposing the Nash232 Sutcliffe efficiency criterion for facilitating its interpretation. The decomposition of Gupta et. al (2009) is:

$233 N S E_{q}=2 \times \frac{\sigma^{\operatorname{sim}}}{\sigma^{a b s}} \times r_{l i n}-\left(\frac{\sigma^{\operatorname{sim}}}{\sigma^{a b s}}\right)^{2}-\left(\frac{\mu^{\operatorname{sim}}-\mu^{a b s}}{\sigma^{0 b s}}\right)^{2}$

234 where $r_{\text {lin }}$ is the linear correlation coefficient between $q^{\operatorname{sim}}$ and $q^{\text {obs }}, \sigma^{\operatorname{sim}}$ is the standard deviation of $235 q^{\operatorname{sim}}, \mu^{\operatorname{sim}}$ is the mean of $q^{\operatorname{sim}}, \sigma^{o b s}$ is the standard deviation of $q^{o b s}$, and $\mu^{o b s}$ is the mean of $q^{o b s}$. The

236 first component uses the linear correlation coefficient for measuring the capacity of the model to

237 reproduce the timing and the shape of the signal, the second component measures the capacity of the 238 model to reproduce the standard deviations of the observations, and the third component measures the 239 capacity of the model to reproduce the mean of the observations.

- The mass balance error $M B E_{q q}$ also known as bias, percent bias or relative bias (Gupta et al., 1999):

$\left.241 \quad M B E_{q}=\frac{\sum_{t=1}^{n t}\left(q_{t}^{\text {sim }}-q_{t}^{o b s}\right)}{\sum_{t=1}^{\text {nt }} q_{t}^{\text {obs }}} \times 100=\frac{\mu^{\text {sim }}-\mu^{o b s}}{\mu^{\text {obs }}} \times 100 \in\right]-100 ;+\infty[$

242 This performance criterion measures the tendency of the simulated values to be larger or smaller than their observed counterparts. If the fit is perfect, $M B E_{q}=0$. If $M B E_{q}>0$, simulated values are, on 
244 average, greater than observed values, and vice versa. This performance criterion can also be used for

245 hydraulic heads by substituting the observed and simulated discharges by the observed and simulated

246 hydraulic heads in equation (7).

247 - The peak error $P E_{q}$ (Aricò et al., 2009):

$\left.248 P E_{q}=\left(\frac{q_{p e a k}^{\text {slm }}}{q_{p e a k}^{\text {obs }}}-1\right) \times 100 \in\right]-100 ;+\infty[$

249 where $q_{p e a k}^{\operatorname{sim}}$ is the simulated peak value, and $q_{p e a k}^{\text {obs }}$ is the observed peak value. This performance

250 criterion measures the capacity of the model to reproduce the peak in the hydrograph. If the observed

251 peak is equal to the simulated peak, $P E_{q}=0$. If $P E_{q}>0$, the simulated peak is greater than the

252 observed peak, and vice versa.

253 - The root mean squared error criterion $R M S_{h}$ :

$254 \quad R^{2} S_{h}=\sqrt{\frac{1}{n t} \times \sum_{t=1}^{n t}\left(h_{t}^{\operatorname{sim}}-h_{t}^{o b s}\right)^{2}} \in[0 ;+\infty[$

255 where $h_{t}^{\text {sim }}$ is the $i^{\text {th }}$ simulated hydraulic head value, and $h_{t}^{\text {obs }}$ is the $i^{\text {th }}$ observed hydraulic head value.

256 This performance criterion measures the discrepancies between observed hydraulic heads and their

257 simulated equivalent for a particular observation point. If the simulated values perfectly match the

258 observed values, $R M S_{h}=0$. The greater the values, the poorer the model.

259 - The hydraulic head variations errors $H H V E_{h}$ :

$\left.260 \quad H H V E_{h}=\left(\frac{h_{\max }^{\operatorname{sim}}-h_{\min }^{\operatorname{sim}}}{h_{\max }^{0 b s}-h_{\min }^{0 b s}}-1\right) \times 100 \in\right]-100 ;+\infty[$ 
261 where $h_{\max }^{\operatorname{sim}}$ is the maximum simulated hydraulic head value, $h_{\min }^{\operatorname{sim}}$ is the minimum simulated hydraulic

262 head value, $h_{\max }^{\text {obs }}$ is the maximum observed hydraulic head value, and $h_{\min }^{\text {obs }}$ is the minimum observed

263 hydraulic head value. This performance criterion is the counterpart of the peak error since it measures

264 the capacity of the model to reproduce the magnitude of hydraulic head variations instead of measuring

265 the capacity of the model to reproduce the peak in the hydrograph.

266 Linear confidence intervals. Linear and nonlinear confidence intervals help quantifying prediction

267 uncertainties. Linear confidence intervals are calculated assuming that the model is linear in the vicinity

268 of parameter values. They are not as accurate as nonlinear confidence intervals for nonlinear models.

269 However, unlike nonlinear confidence intervals, linear confidence intervals only require trivial amount of

270 execution time. Therefore, they are often the only confidence intervals calculable for physically-based

271 and spatially-distributed models with lengthy execution times.

272 Linear confidence intervals on predictions have the form:

$273 \quad z_{l}^{\prime} \pm t_{s}\left(n, 1.0-\frac{\alpha}{2}\right) \times s_{z_{l}^{\prime}}$

274 where $z_{l}^{\prime}$ is the $\mathrm{I}^{\text {th }}$ simulated prediction, $t_{S}\left(n, 1.0-\frac{\alpha}{2}\right)$ is the Student-t distribution with

$275 n=($ nobs - npar $)$ and $\alpha=0.05$ for $95 \%$ confidence intervals, and $s_{z_{I}^{r}}$ is the standard deviation of the

276 prediction calculated as:

$277 \quad s_{z_{I}^{I}}=\left[\sum_{i=1}^{n p a r} \sum_{j=1}^{n p a r} \frac{\partial z_{l}^{I}}{\partial b_{j}} \times \boldsymbol{V}(\boldsymbol{b}) \times \frac{\partial z_{l}^{l}}{\partial b_{i}}\right]^{1 / 2}$

278 where npar is the number of parameters, $\frac{\partial z_{l}^{g}}{\partial b_{j}}$ is the sensitivity of the $\mathrm{I}^{\text {th }}$ prediction $z_{l}^{y}$ with respect to the

$279 j^{\text {th }}$ parameter $b_{j}$ and $\boldsymbol{V}(\boldsymbol{b})$ is the parameter variance-covariance matrix. 


\section{Conceptual model}

281 The synthetic catchment is inspired by a real catchment located in the Condroz region of Belgium. This

282 region is characterized by a succession of limestone synclines and sandstone anticlines. The surface

283 materials of the synthetic catchment are assigned using a criterion combining elevation and slope

284 constraints. All surface materials are assigned a series of parameters required for simulating

285 interception, evapotranspiration, and surface flow processes. Appropriate values for these parameters

286 are extracted from the literature. They are listed in Appendix A. The subsurface materials of the

287 synthetic catchment are defined to represent the typical geology of the Condroz region: sandstones,

288 limestones, and shales constitute, from the crests to the center of the valley, the subsurface materials of

289 the synthetic catchment. Additionally, these formations are covered by alluvial deposits and loam. All

290 subsurface materials are assigned a series of parameters required for simulating subsurface flow

291 processes. Appropriate values for these parameters, including van Genuchten parameters governing

292 saturation-pressure relations in the vadose zone, are extracted from the literature. They are listed in

293 Appendix B. The synthetic catchment is illustrated in Figure 1.

294 The horizontal element size of the reference model progressively increases from $25 \mathrm{~m}$ near the surface

295 water network to $250 \mathrm{~m}$ far from the surface water network. The layer thickness progressively increases

296 from $1 \mathrm{~m}$ for the top layers corresponding to the vadose zone to $30 \mathrm{~m}$ for the bottom layers

297 corresponding to the saturated zone (5 layers of $1 \mathrm{~m}, 1$ layer of $5 \mathrm{~m}, 1$ layer of $10 \mathrm{~m}$, and 1 layer of

$29830 \mathrm{~m}$ ). The reference model is composed of 153,027 nodes and 269,872 elements. The grid of the

299 reference model is illustrated in Figure 2. Critical-depth boundary conditions are assigned to boundary

300 nodes of the surface domain. This type of boundary condition forces the water elevation at the

301 boundary to be equal to the water elevation for which the energy of the flowing water relatively to the

302 stream bottom is minimum (Therrien et al., 2012). No-flow boundary conditions are assigned to 
boundary nodes of the subsurface domain. Water depths and hydraulic heads extracted from

304 preliminary simulations performed with the reference model are used as initial conditions for the surface domain and the subsurface domain, respectively.

The set of observation points is constituted of 1 gauging station for discharge (G1) and 12 piezometers

GAL2) and four wells (W1 to W4) are used to simulate groundwater withdrawals. The set of observation points and the galleries and wells are illustrated in Figure 1. As the models with a coarse grid are run

312 Tiedeman, 2007, p. 215). These monthly averaged discharge and hydraulic heads constitute the set of 313 reference observations used to calculate performance criteria for the simplified models. The reference 314 simulation is subdivided into warm-up, calibration, and validation periods. The warm-up is necessary for 315 obtaining simulated values independent of the initial conditions. Discharge and hydraulic heads produced during the warm-up period are not included in the set of reference observations. Performance

317 criteria are only calculated for discharge and hydraulic heads produced during calibration and validation 318 periods. Linear confidence intervals on predictions are calculated for the validation period.

\section{Results and Discussion}

320 The models developed for evaluating the effects of spatial discretization on model performance and 321 model prediction uncertainties are referred as the $250 \mathrm{~m}, 500 \mathrm{~m}, 750 \mathrm{~m}$, and $1000 \mathrm{~m}$ models. They are 322 characterized by a constant element size of $250 \mathrm{~m}, 500 \mathrm{~m}, 750 \mathrm{~m}$, and $1000 \mathrm{~m}$, respectively. As opposed 323 to the reference model, they are not refined near the surface water network. The purpose here consists 324 in evaluating the effects of ignoring such a refinement on the simulation of discharge and hydraulic

325 heads. Additionally, it also allows evaluating whether calibration can compensate for the errors induced 
326 by ignoring such a refinement. As the reference model, they each have 8 layers (5 layers of $1 \mathrm{~m}, 1$ layer

327 of $5 \mathrm{~m}, 1$ layer of $10 \mathrm{~m}$, and 1 layer of $30 \mathrm{~m}$ ). The number of nodes, the number of elements, and the

328 execution times of the $250 \mathrm{~m}, 500 \mathrm{~m}, 750 \mathrm{~m}$, and $1000 \mathrm{~m}$ models are presented in Table 1. The

329 comparison between the execution time of each model clearly shows the usefulness of coarsening grid

330 size for reducing the execution times.

331 4.1 Comparison of model performance before calibration

332 Graphs of model fit and performance criteria are used together for comparing the performance of the

$333250 \mathrm{~m}, 500 \mathrm{~m}, 750 \mathrm{~m}$, and $1000 \mathrm{~m}$ models run with the same parameter values than those used in the

334 reference model i.e. without any calibration.

335 Graphs comparing reference values of discharge and hydraulic heads produced with the reference

336 model and their simulated equivalent obtained with the models with a coarse grid indicate that

337 discharge is most often underestimated during low flow periods and overestimated during high flow

338 periods (Figure 3-A). The underestimation is almost identical for each model. The overestimation is

339 higher for models with a coarse horizontal spatial discretization. This is clearly visible on peak discharge.

340 Graphs of unweighted simulated values versus weighted residuals support these findings. These graphs

341 particularly highlight the underestimation of discharge by each model during low flow periods and the

342 overestimation of discharge during high flow rates by the coarsest ones (Figure 3-B).

343 The influence of horizontal spatial discretization on hydraulic head simulation is less visible (Figure 3-A).

344 However, weighted residuals are in general greater for the coarsest models (Figure 3-B). This shows that

345 the simulation of hydraulic heads is poorer with the coarsest models.

346 Graphical model fit analysis is confirmed by performance criteria. As the grid is coarsened, NSE $E_{q}$ values

347 tend to decrease and $R M S_{h}$ values tend to increase (Figure 4-A). This indicates that simulation of both 
discharge and hydraulic heads is deteriorated. For discharge, Gupta's decomposition of NSE $E_{q}$ shows

that the standard deviation of discharge is overestimated by the coarsest models (Table 2). This is visible to the greater values of Gupta's second terms. This is also supported by the increasing values of $P E_{q}^{y r} 1$

351 and $P E_{q}^{y r 2}$ showing that peak discharge, and so the standard deviation of the hydrograph, are

352 overestimated by the coarsest models (Table 2). Gupta's decomposition also shows that the $250 \mathrm{~m}$ model lacks to properly simulate the average magnitude of discharge. This is why $N S E_{q}$ value for this model is lower than $N S E_{q}$ value for the $500 \mathrm{~m}$ model. This is confirmed by the values of $M B E_{q}$ which shows that the $250 \mathrm{~m}$ model underestimates the average magnitude of discharge by almost $15 \%$. This is related to the fact that the underestimation of discharge during low flow periods is not compensated by

357 the overestimation of discharge during high flow rates as it is the case for the other models. For

358 hydraulic heads, the absolute values of $M B E_{h}$ are in general low for each model (Table 3). This indicates that models are not significantly biased in terms of hydraulic heads. However, the range of $M B E_{h}$ values

360 is in general wider for the coarsest models. Although the absolute values of $H H V E_{h}^{y r 1}$ and $H H V E_{h}^{y r 2}$

361 are in general greater for the coarsest models, the ranges of $H H V E_{h}^{y r} 1$ and $H H V E_{h}^{y r 2}$ are similar for 362 each model (Table 3).

363 The comparison of model performance performed in this section indicates that coarsening the grid 364 mainly deteriorates the simulation of discharge. Common to each model tested, the underestimation of 365 discharge during low flow periods is due to a poor representation of the surface water network which 366 precludes from properly simulating groundwater-surface water interactions that constitute the key 367 component of the hydrograph during dry seasons. As previously mentioned, this problem of poor 368 representation of the surface water network is also mentioned by Refsgaard (1997) and Vázquez et al. 369 (2002). The overestimation of discharge by the coarsest models during high flow periods is related to 
the use of large elements which induces a smoothing of surface slopes and facilitates runoff, especially

371 during wet seasons. The object of the next section is to evaluate how calibration can compensate for the

372 errors induced by coarsening the grid.

\subsection{Comparison of model performance after calibration}

374 A sensitivity analysis is performed for each parameter prior to the calibration. The composite scaled

375 sensitivities calculated on the calibration period ( 24 discharge observations and 288 hydraulic head

376 observations) for each parameter included in the calibration (32 parameters) are illustrated in Figure 5.

377 Whatever the spatial discretization, the ranking of the most sensitive parameters and the magnitude of

378 the composite scaled sensitivities are almost identical. This suggests that parameter sensitivities are not

379 highly dependent on the grid size. The most sensitive parameter is always the van Genuchten

380 parameters $\beta_{\mathrm{vG}}$ of Mat I - loam and Mat II - alluvial deposits (top layers of the models). This parameter,

381 related to the pore-size distribution in the porous medium, defines the shape of the water retention

382 curve. The other most sensitive parameters are the hydraulic conductivity K of Mat IV - limestones 2,

383 probably because most of the observation points are located in this material, and the van Genuchten

384 parameter $\beta_{\mathrm{vG}}$ of Mat IV - limestones 1, Mat V - limestones 2 and Mat $\mathrm{VI}$ - sandstones. The van

385 Genuchten parameter $\alpha_{v G}$ of Mat IV - limestones 1, Mat V - limestones 2 and Mat VI - sandstones as

386 well as the hydraulic conductivity $\mathrm{K}$ of Mat I - loam have also a relatively high sensitivity. The fact that

387 van Genuchten parameters, especially the parameter $\beta_{v G}$ of the materials constituting the top layers of

388 the models, are systematically among the most sensitive parameters suggests that fully-integrated and

389 physically-based models are highly sensitive to parameters governing the infiltration process in the

390 vadose zone and the groundwater recharge.

391 The improvement of model performance with calibration with PEST is evaluated using the same graphs

392 of model fit and the same performance criteria than in the previous section. Graphs of model fit show 
that calibration significantly improves the simulation of discharge and, to a lesser extent, hydraulic

394 heads for each model (Figure 6-A). Additionally, after calibration, weighted residuals are almost

395 randomly distributed which suggests that calibrated models are less biased (Figure 6-B). Performance

396 criteria support these findings since $N S E_{q}$ and $R M S_{h}$ values are significantly greater and lower,

397 respectively, after calibration (Figure 4-B). The values of Gupta's terms together with the values of

$398 M B E_{q}, P E_{q}^{y r 1}$, and $P E_{q}^{y r 2}$ calculated for the calibrated models indicate that both the mean and the

399 standard deviation of flow rates are better simulated (Table 4). The improvement of hydraulic head

400 simulation is not so clear. When observed and simulated hydraulic heads are shifted, the calibration

401 process strives for reducing this systematic error. Therefore, the improvement of average hydraulic

402 head magnitudes is sometimes obtained to the detriment of the improvement of hydraulic head

403 variations. This is why the absolute values and the range of $M B E_{h}$ are most often lower than those

404 obtained with the models before calibration, while the absolute values and the ranges of $H H V E_{h}^{y r} 1$ and

$405 H H V E_{h}^{y r 2}$ are identical or even greater than those obtained with the models before calibration (Table

406 5). This shows that calibration has limitations. Furthermore, although most of them are still within

407 reasonable ranges, some calibrated parameter values are far from their values in the reference model

408 (Table 6). Such an observation is only possible for synthetic catchments for which reference parameter

409 values are exactly known. The only verification possible for real catchments consists in making sure that

410 calibrated parameter values are plausible with regards to field or laboratory data. However, as shown by

411 Brunner et al. (2012b), accurately evaluating certain combinations of parameters can be sufficient to

412 produce predictions with a good level of confidence, which means that it is not always necessary to

413 accurately evaluate each parameter individually. Therefore, in spite of its limitations, calibration is

414 essential for improving model performance, either inside or outside the calibration period. As illustrated

415 in Figure 7, calibration indeed leads to greater values of $N S E_{q}$ and lower values of $R M S_{h}$ also during the 
416 validation period. The object of the next section is to evaluate whether grid coarsening leads to greater

417 model prediction uncertainties.

\section{$418 \quad 4.3$ Comparison of model prediction uncertainties}

419 Linear confidence intervals on predictions are calculated for discharge and hydraulic heads simulated in

420 the validation period with the calibrated models. They are illustrated in Figures 8 to 11 . The linear

421 confidence intervals calculated for discharge are almost identical for the $250 \mathrm{~m}, 500 \mathrm{~m}$, and $750 \mathrm{~m}$

422 models. They are even sometimes narrower for the $500 \mathrm{~m}$ or the $750 \mathrm{~m}$ models than for the $250 \mathrm{~m}$

423 model. However, especially for high flow periods, they are far wider for the $1000 \mathrm{~m}$ model. The linear

424 confidence intervals calculated for hydraulic heads are quite similar for each model and once more the

425 narrowest intervals are not always obtained for the $250 \mathrm{~m}$ model.

426 The analysis of model prediction uncertainties indicates that coarsening model grid mainly influences

427 the uncertainties on discharge predictions. This is not surprising since the comparison of model

428 performance shows that discharge simulation is more sensitive to grid size than hydraulic head

429 simulation. However, the uncertainties on discharge predictions significantly increase only for a very

430 coarse grid and even if graphs of model fit and performance criteria suggest that the model is good.

431 Therefore, to some extent, it is possible to simplify a model by coarsening its grid without increasing

432 model prediction uncertainties. This is consistent with the study of Brunner et al. (2012b) focusing on

433 parameter identifiability and predictive uncertainty. This study highlights the sliding nature of

434 complexity versus simplicity and shows that predictive power may lose little if the model is simplified

435 appropriately.

4.4 Guidelines for selection of a proper horizontal spatial discretization for large-scale flow modelsA

437 synthetic catchment can always be considered as far from reality. Therefore, caution should be

438 exercised when using results of this study for selecting a proper horizontal spatial discretization for a 
given site-specific study. However, a series of general guidelines can be drawn from this study. As an

440 example, in the framework of use of paired simple and complex models to reduce predictive bias and

441 quantify uncertainty (Doherty and Christensen, 2011), these guidelines could be used for helping

442 modelers selecting a proper horizontal spatial discretization for the simple model.

443 Large-scale physically-based and spatially-distributed model development consists in finding a

444 compromise between model accuracy and model portability i.e. maximizing model performance and

445 minimizing prediction uncertainty while limiting the execution times. Given the results of this study, for

446 catchments of a few hundreds square kilometer, an element size of the order of $500 \mathrm{~m}$ is the best

447 compromise for obtaining good model performance with tractable execution times without significantly

448 increasing prediction uncertainty. With a coarser horizontal spatial discretization, the relative reduction

449 of execution times is limited with respect to the probability of increasing prediction uncertainty. With a

450 finer horizontal spatial discretization, the execution times strongly increase without any significant

451 reduction of prediction uncertainty.

\section{$452 \quad 5$ Summary and Conclusions}

453 The present study focuses on the effects of horizontal spatial discretization on large-scale flow model

454 performance and model prediction uncertainties using a fully-integrated hydrological model of a

455 synthetic catchment. This kind of large-scale fully-integrated hydrological model is increasingly used in

456 water management for predicting the evolution of both the integrated response (discharge) and the

457 distributed response (hydraulic heads) of catchments. However, these models are characterized by

458 lengthy execution times and model grids are often coarsened for reducing these execution times.

459 Therefore, it is crucial to evaluate the influence of such a grid coarsening on model performance and

460 model prediction uncertainties. This study shows that: 
- Grid coarsening mainly influences the simulation of discharge with an underestimation of discharge during low flow periods and a progressive overestimation of peak discharge as horizontal spatial discretization is coarsened. This is related to a poor representation of the spatial discretizations.

474 As uncertainty analyses have become essential in natural system modeling, this is encouraging since grid

475 coarsening greatly reduces execution times and such analyses can only be performed for model with 476 relatively short execution times.

\section{References}

478 Anderman, E., Hill, M.C., Poeter, E.P., 1996. Two-dimensional advective transport in ground-water flow 479 parameter estimation. Ground Water 34(6), 1001-1009.

480 Aricò, C., Nasello, C., Tucciarelli, T., 2009. Using steady-state water level data to estimate channel 481 roughness and discharge hydrograph. Advances in Water Resources 32(8), 1223-1240. 

rates in heterogeneous aquifers. Water Resources Research 42(W01420).

Beyer, C., Bauer, S., Kolditz, O., 2006. Uncertainty assessment of contaminant plume length estimates in 485 heterogeneous aquifers. Journal of Contaminant Hydrology 87(1-2), 73-95.

Brunner, P., Doherty, J., Simmons, C.T., 2012a. Uncertainty assessment and implications for data

487 acquisition in support of integrated hydrologic models. Water Resources Research 48(W07513).

488 Brunner, P., Simmons, C.T., 2012b. HydroGeoSphere : A fully-integrated, physically-based hydrological 489 model. Ground Water 50(2), 170-176.

490 Doherty, J., 2005. PEST - Model-independent parameter estimation - User Manual $-5^{\text {th }}$ edition.

491 Watermark Numerical Computing.

492 Dohery, J., Christensen, S., 2011. Use of paired simple and complex models to reduce predictive bias and 493 quantify uncertainty. Water Resources Research 47(W12534).

494 Downer, C.W., Ogden, F.L., 2004. Appropriate vertical discretization of Richards' equation for two495 dimensional watershed-scale modelling. Hydrological Processes 18, 1-22.

496 Ebel, B., Loague, K., 2006. Physics-based hydrologic-response simulation: seeing through the fog of 497 equifinality. Hydrological Processes 20(13), 2887-2900.

498 Frei, S., Fleckenstein, J.H., Kollet, S.J., Maxwell, R.M., 2009. Patterns and dynamics of river-aquifer 499 exchange with variably-saturated flow using a fully-coupled model. Journal of Hydrology 375, 383-393.

500 Goderniaux, P., Brouyère, S., Fowler, H., Blenkinsop, S., Therrien, R., Orban Ph., Dassargues, A., 2009. 501 Large scale surface-subsurface hydrological model to assess climate change impacts on groundwater 502 reserves. Journal of Hydrology 373(1-2), 122-138. 
503 Goderniaux, P., Brouyère, S., Blenkinsop, S., Burton, A., Fowler, H., Orban Ph., Dassargues, A., 2011.

504 Modeling climate change impacts on groundwater resources using transient stochastic climatic

505 scenarios. Water Resources Research 47 (W12516).

506 Gupta, H., Sorooshian, S., Yapo, P., 1999. Status of automatic calibration for hydrologic models:

507 comparison with multilevel expert calibration. Journal of Hydrologic Engineering 4(2), 135-143.

508 Gupta, H., Kling, H., Yilmaz, K., Martinez, G., 2009. Decomposition of the mean squared error and NSE

509 performance criteria: implications for improving hydrological modelling. Journal of Hydrology, 377(1-2),

$510 \quad 80-91$.

511 Hill, M.C., 1992. A computer program (MODFLOWP) for estimating parameters of a transient, three-

512 dimensional, ground-water flow model using nonlinear regression. Open-File Report 91-484, U.S.

513 Geological Survey.

514 Hill, M.C., Cooley, R., Pollock, D., 1998. A controlled experiment in groundwater flow model calibration 515 using nonlinear regression. Ground Water 36(3), 520-535.

516 Hill, M.C., Tiedeman, C.R., 2007. Effective groundwater model calibration with analysis of sensitivities,

517 predictions and uncertainty. Hoboken, NJ, USA: John Wiley \& Sons.

518 Irvine, D.J., Brunner, P., Hendricks Franssen, H.-J., Simmons C.T., 2012. Heterogeneous or

519 homogeneous? Implications of simplifying heterogeneous streambeds in models of losing streams.

520 Journal of Hydrology 424-425, 16-23.

521 Kristensen, K.J., Jensen, S.E., 1975. A model for estimating actual evapotranspiration from potential 522 evapotranspiration. Nordic Hydrology 6, 170-188. 
523 Legates, D., McCabe, G., 1999. Evaluating the "goodness-of-fit" measures in hydrologic and

524 hydroclimate model validation. Water Resources Research 35(1), 233-241.

525 Li, Q., Unger, A., Sudicky, E., Kassenaar, D., Wexler, E., Shikaze, S., 2008. Simulating the multi-seasonal 526 response of a large-scale watershed with a 3D physically-based hydrologic model. Journal of Hydrology $527 \quad 357(3-4), 317-336$.

528 Meyerhoff, S.B., Maxwell, R.M., 2011. Quantifying the effects of subsurface heterogeneity on hillslope 529 runoff using a stochastic approach. Hydrogeology Journal 19, 1515-1530.

530 Moriasi, D., Arnold, J., Van Liew, M., Binger, R., Harmel, R., Veith, T., 2007. Model evaluation guidelines

531 for systematic quantification of accuracy in watershed simulations. Transactions of the ASABE 50(3), $532885-900$.

533 Nash, J., Sutcliffe, J., 1970. River flow forecasting through conceptual models I- A discussion of 534 principles. Journal of Hydrology 10(3), 282-290.

535 Poeter, E.P., McKenna, S., 1995. Reducing uncertainty associated with ground-water flow and transport 536 predictions. Ground Water 33(6), 899-904.

537 Poeter, E.P., Hill, M.C., 1997. Inverse models: a necessary next step in ground-water modeling. Ground 538 Water 35(2), 250-260.

539 Refsgaard, J.C, 1997. Parameterisation, calibration and validation of distributed hydrological models.

540 Journal of Hydrology 198, 69-97.

541 Refsgaard, J.C., Henriksen, H., 2004. Modelling guidelines - terminology and guiding principles.

542 Advances in Water Resources 27(1), 71-82. 
543 Schäfer, D., Schlenz, B., Dahmke, A., 2004. Evaluation of exploration and monitoring methods for

544 verification of natural attenuation using the virtual aquifer approach. Biodegradation 15(6), 453-465.

545 Sciuto, G., Diekkrüger, B., 2010. Influence of soil heterogeneity and spatial discretization on catchment 546 water balance modeling. Vadose Zone Journal 9, 955-969.

547 Skahill, B., Doherty, J., 2006. Efficient accommodation of local minima in watershed model calibration. 548 Journal of Hydrology 329(1-2), 122-139.

549 Therrien, R., McLaren, R., Sudicky, E., Park, Y.-J.., 2012. HydroGeoSphere - A three-dimensional

550 numerical model describing fully-integrated subsurface and surface flow and solute transport. Manual,

551 Groudnwater Simulations Group.

552 Vázquez R.F., Feyen, L., Feyen, J., Refsgaard, J.C., 2002. Effect of grid size on effective parameters and 553 model performance of the MIKE-SHE code. Hydrological Processes 16, 355-372.

554 Weglarczyk, S., 1998. The interdependence and applicability of some statistical quality measures for 555 hydrological models. Journal of Hydrology 206(1-2), 98-103. 
558 Appendices

559 Appendice A: Interception, evapotranspiration and surface flow parameters used in the synthetic case

\begin{tabular}{|c|c|c|c|c|}
\hline Interception and evapotranspiration & Mat 1 & Mat 2 & Mat 3 & Mat 4 \\
\hline LAI [-] & 0.40 & 3.53 & 5.12 & - \\
\hline $\mathrm{L}_{\mathrm{r}}[\mathrm{m}]$ & 0 & 2.30 & 2.90 & - \\
\hline $\mathrm{L}_{\mathrm{e}}[\mathrm{m}]$ & 2.00 & 2.00 & 2.00 & - \\
\hline$\theta_{\mathrm{e} 2} \& \theta_{\mathrm{t} 2}[-]$ & 0.60 & 0.60 & 0.60 & - \\
\hline$\theta_{\mathrm{e} 1} \& \theta_{\mathrm{t} 1}[-]$ & 0.96 & 0.96 & 0.96 & - \\
\hline $\mathrm{C}_{1}[-]$ & 0.31 & 0.31 & 0.31 & - \\
\hline$C_{2}[-]$ & 0.15 & 0.15 & 0.15 & - \\
\hline$C_{3}[-]$ & 10.00 & 10.00 & 10.00 & - \\
\hline$C_{\text {int }}[\mathrm{m}]$ & $5.00 \times 10^{-5}$ & $5.00 \times 10^{-5}$ & $5.00 \times 10^{-5}$ & - \\
\hline$S_{\text {int }}^{0}[m]$ & 0 & 0 & 0 & - \\
\hline Surface flow & Mat 1 & Mat 2 & Mat 3 & Mat 4 \\
\hline$n_{x x} \& n_{y y}\left[m^{-1 / 3} s\right]$ & 0.012 & 0.200 & 0.600 & 0.025 \\
\hline $\mathbf{H}_{\text {sto }}[\mathrm{m}]$ & 0.002 & 0.002 & 0.002 & 0.002 \\
\hline $\mathrm{L}_{\mathrm{c}}[\mathrm{m}]$ & $1.00 \times 10^{-1}$ & $1.00 \times 10^{-1}$ & $1.00 \times 10^{-1}$ & $1.00 \times 10^{-1}$ \\
\hline
\end{tabular}

$560 L A I=$ Leaf Area Index; $L_{r}=$ root depth; $L_{c}=$ evaporation depth; $\theta_{\mathrm{e} 2} \& \theta_{\mathrm{t} 2}$ and $\theta_{\mathrm{e} 1} \& \theta_{\mathrm{t} 1}=$ evaporation and

561 transpiration limiting saturations; $C_{1}, C_{2}$, and $C_{3}=$ transpiration fitting parameters; $C_{\text {int }}=$ canopy storage

562 parameter; $S^{0}{ }_{i n t}=$ initial interception storage; $n_{x x} \& n_{y y}=$ Manning roughness coefficients; $H_{\text {sto }}=$ rill

563 storage height; $L_{c}=$ coupling length. 
Parameter values are extracted from the literature:

- for parameters related to interception and evapotranspiration processes, see Andersen et al., 2002; Asner et al., 2003; Canadell et al., 1996; Dickinson et al., 1991; Goderniaux, 2010; Graham and Kilde, 2002; Islam, 2004; Kristensen and Jensen, 1975;Li et al., 2008; Panday and Huyakorn, 2004; Schroeder et al., 2004; Therrien et al., 2005; Vázquez et al., 2002; Vázquez and Feyen, 2003.

- for parameters related to surface flow processes, see Brutsaert, 2005; Fetter, 2001; Hornberger et al., 1998; Jones, 2005; Li et al., 2008; McCuen, 1989.

\section{Appendice B: Subsurface flow parameters used in the synthetic case}

\begin{tabular}{lllllll} 
Subsurface flow & Mat I & Mat II & Mat III & Mat IV & Mat V & Mat VI \\
\hline $\mathbf{K}\left[\mathrm{ms}^{-1}\right]$ & $5.00 \times 10^{-7}$ & $1.00 \times 10^{-6}$ & $1.00 \times 10^{-5}$ & $1.00 \times 10^{-4}$ & $2.50 \times 10^{-4}$ & $5.00 \times 10^{-5}$ \\
$\mathbf{S}_{\mathrm{S}}\left[\mathrm{m}^{-1}\right]$ & $1.00 \times 10^{-4}$ & $1.00 \times 10^{-4}$ & $1.00 \times 10^{-4}$ & $1.00 \times 10^{-4}$ & $1.00 \times 10^{-4}$ & $1.00 \times 10^{-4}$ \\
$\boldsymbol{\theta}_{\mathrm{s}}[-]$ & $4.10 \times 10^{-1}$ & $4.10 \times 10^{-1}$ & $2.50 \times 10^{-2}$ & $1.00 \times 10^{-1}$ & $1.00 \times 10^{-1}$ & $7.50 \times 10^{-2}$ \\
$\mathbf{S}_{\mathrm{wr}}[-]$ & $9.76 \times 10^{-2}$ & $9.76 \times 10^{-2}$ & 0 & 0 & 0 & 0 \\
$\boldsymbol{\alpha}_{\mathrm{vG}}\left[\mathrm{m}^{-1}\right]$ & 2.67 & 2.67 & $6.08 \times 10^{-12}$ & $3.65 \times 10^{-2}$ & $3.65 \times 10^{-2}$ & $3.65 \times 10^{-2}$ \\
$\boldsymbol{\beta}_{\mathrm{vG}}[-]$ & 1.45 & 1.45 & 0.62 & 1.83 & 1.83 & 1.83 \\
$\boldsymbol{V}_{\mathrm{vG}}[-]$ & $1-1 / \beta_{\mathrm{vG}}$ & $1-1 / \beta_{\mathrm{vG}}$ & $38,671.00$ & $1-1 / \beta_{\mathrm{vG}}$ & $1-1 / \beta_{\mathrm{vG}}$ & $1-1 / \beta_{\mathrm{vG}}$
\end{tabular}

$573 \mathrm{~K}=$ saturated hydraulic conductivity; $\mathrm{S}_{\mathrm{S}}=$ specific storage; $\theta_{\mathrm{s}}=$ saturated water content; $\mathrm{S}_{\mathrm{wr}}=$ residual

574 water saturation; $\alpha_{v G}, \beta_{v G}$, and $\gamma_{v G}=$ van Genuchten parameters.

575 Parameter values are extracted from the literature: Cherry, 1979; Jones, 2005; Radcliffe, 2000; Ramos da Silva et al., 2008; Roulier et al., 2006. 


\section{Figure captions}

581 Figure 1 The reference model is assigned surface materials depending on elevation and slope constraints

582 and subsurface materials following the typical syncline structure of catchments located in the Condroz

583 region of Belgium. A gauging station (G1) and twelve piezometers (Pz1 to Pz12) are used to obtain

584 reference observations in terms of discharge and hydraulic heads, respectively. Two galleries (GAL1 and

585 GAL2) and four wells (W1 to W4) are used to simulate groundwater withdrawals.

586 Figure $\mathbf{2}$ The grid of the reference model is refined horizontally (element side length from $25 \mathrm{~m}$ to

$587250 \mathrm{~m}$ ) and vertically (layer thickness from $1 \mathrm{~m}$ to $30 \mathrm{~m}$ ). The total number of nodes is 153,027.

588 Figure 3 A. As spatial discretization gets coarser, discharge simulation and, to a lesser extent, hydraulic

589 head simulation is progressively deteriorated. B. While each model underestimates discharge during low 590 flow periods, discharge during high flow periods is only overestimated by the coarsest models. This is 591 highlighted by the graphs of weighted residuals.

592 Figure $4 \mathrm{~A}$. As horizontal spatial discretisation gets coarser, $N S E_{q}$ values are in general lower and $R M S_{h}$

593 values are in general higher, this indicates that the simulation of both discharge and hydraulic heads are

594 progressively deteriorated. B. The higher values of $N S E_{q}$ and the lower values of $R M S_{h}$ obtained with the 595 calibrated models indicate that calibration significantly improves the simulation of both discharge and 596 hydraulic heads.

597 Figure 5 Whatever the spatial discretization, the ranking of the most sensitive parameters and the 598 magnitude of the composite scaled sensitivities are almost similar. This suggests that parameter 599 sensitivities are not highly dependent on the grid size. 
600 Figure 6 Calibration significantly improves model performance even for the coarsest models. B.

601 Weighted residuals obtained with the calibrated models are almost randomly distributed. This indicates 602 that calibration reduces model bias.

603 Figure 7 Values of $N S E_{q}$ and $R M S_{h}$ calculated for the validation period indicate that calibration also

604 improves model performance outside the calibration period.

605 Figure 8 The 95\% linear confidence intervals calculated for discharge only increase significantly for the 606 coarsest model.

607 Figures $\mathbf{9}$ to $\mathbf{1 1}$ The $95 \%$ linear confidence intervals calculated for hydraulic heads are quite similar for 608 each model. 


\section{Table captions}

612 Table 1 Comparison of the number of nodes, number of elements, and execution times of the $250 \mathrm{~m}$,

$613500 \mathrm{~m}, 750 \mathrm{~m}$, and $1000 \mathrm{~m}$ models. The gain in execution time is tremendous when element size is

614 increased.

615 Table 2 Values of $N S E_{q}, M B E_{q}, P E_{q}^{y r 1}$, and $P E_{q}^{y r 2}$ calculated for the $250 \mathrm{~m}, 500 \mathrm{~m}, 750 \mathrm{~m}$, and $1000 \mathrm{~m}$

616 models. When spatial discretisation gets coarser, the variance of the hydrograph is poorly simulated

617 (Gupta's 2 ${ }^{\text {nd }}$ term).

618 Table 3 Values of $M B E_{h}, H H V E_{h}^{y r 1}$, and $H H V E_{h}^{y r 2}$ calculated for the $250 \mathrm{~m}, 500 \mathrm{~m}, 750 \mathrm{~m}$, and $1000 \mathrm{~m}$ 619 models.

620 Table 4 Values of $N S E_{q}, M B E_{q}, P E_{q}^{y r 1}$, and $P E_{q}^{y r 2}$ calculated for the calibrated $250 \mathrm{~m}, 500 \mathrm{~m}, 750 \mathrm{~m}$,

621 and $1000 \mathrm{~m}$ models. Values in green are improved with regards to the corresponding models before

622 calibration. Values in red are deteriorated with regards to the corresponding forward models.

623 Table 5 Values of $M B E_{h}, H H V E_{h}^{y r 1}$, and $H H V E_{h}^{y r 2}$ calculated for the calibrated $250 \mathrm{~m}, 500 \mathrm{~m}, 750 \mathrm{~m}$,

624 and $1000 \mathrm{~m}$ models. Values in green are improved with regards to the corresponding models without

625 calibration. Values in red are deteriorated with regards to the corresponding forward models.

626 Table 6 Comparison of the reference value of the most sensitive parameters and their value after

627 calibration. 


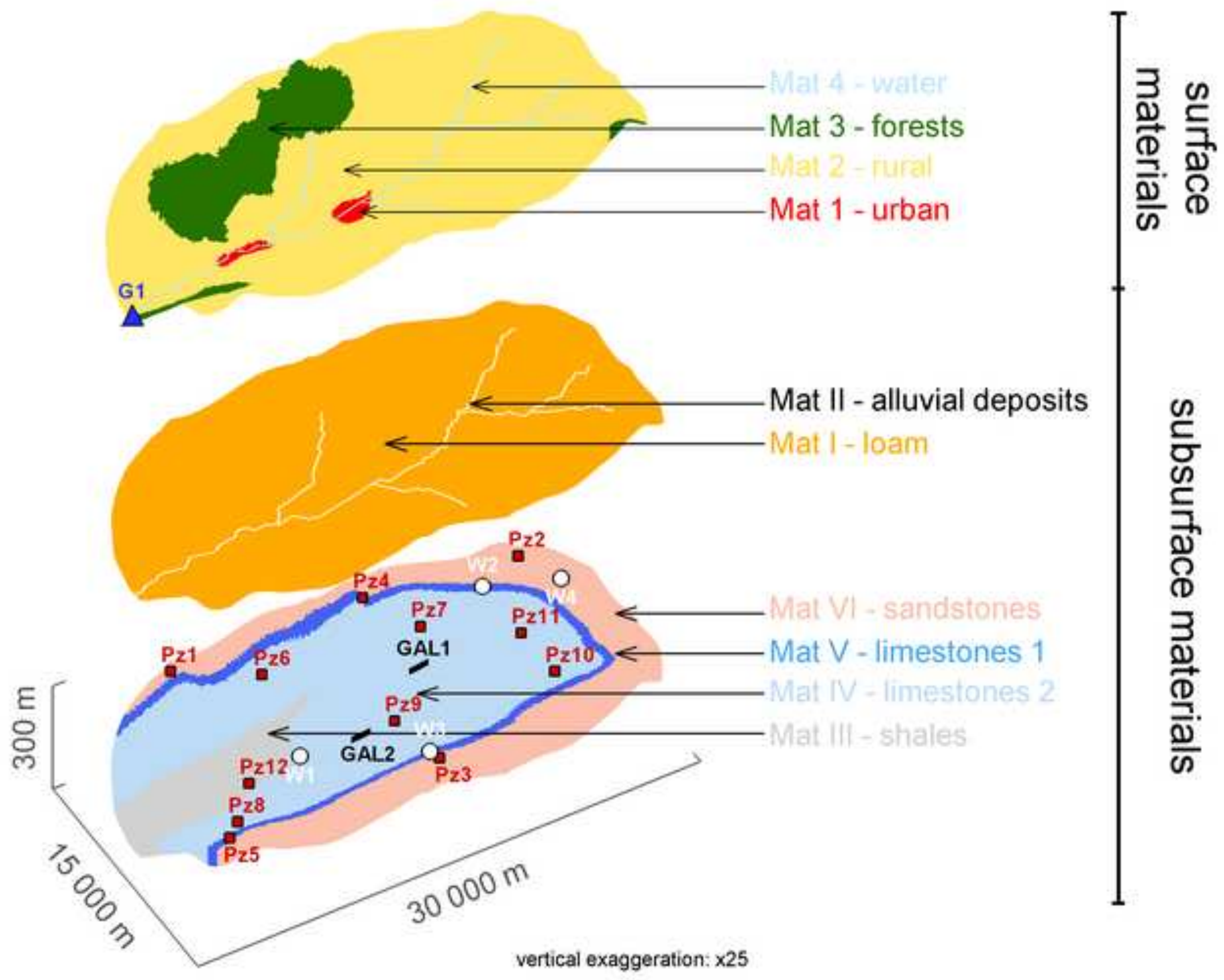


Click here to download high resolution image

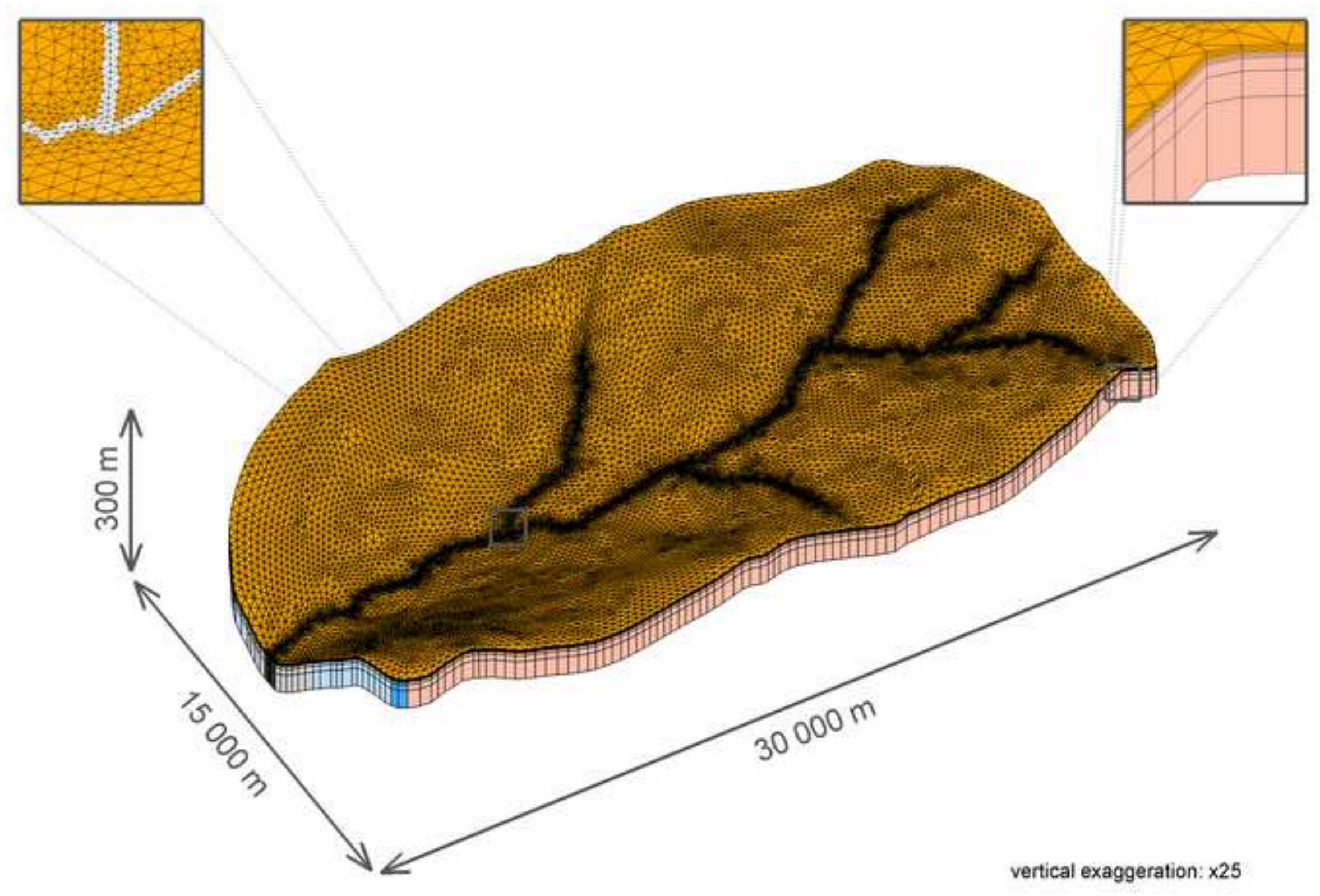

Figure_2 
Click here to download high resolution image

A. reference vs simulated values

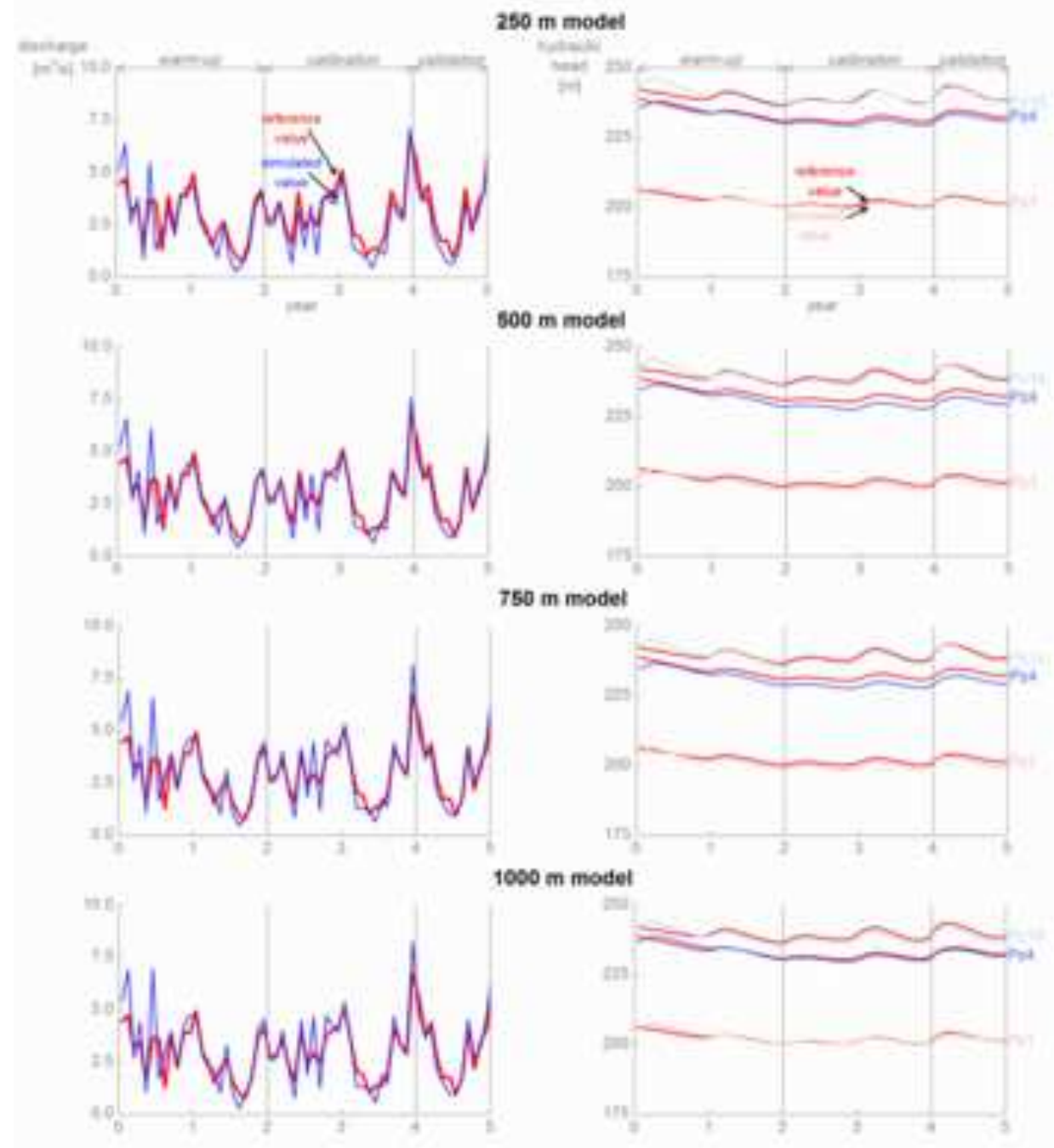

B. simulated values vs weighted residuals

$250 \mathrm{~m}$ model

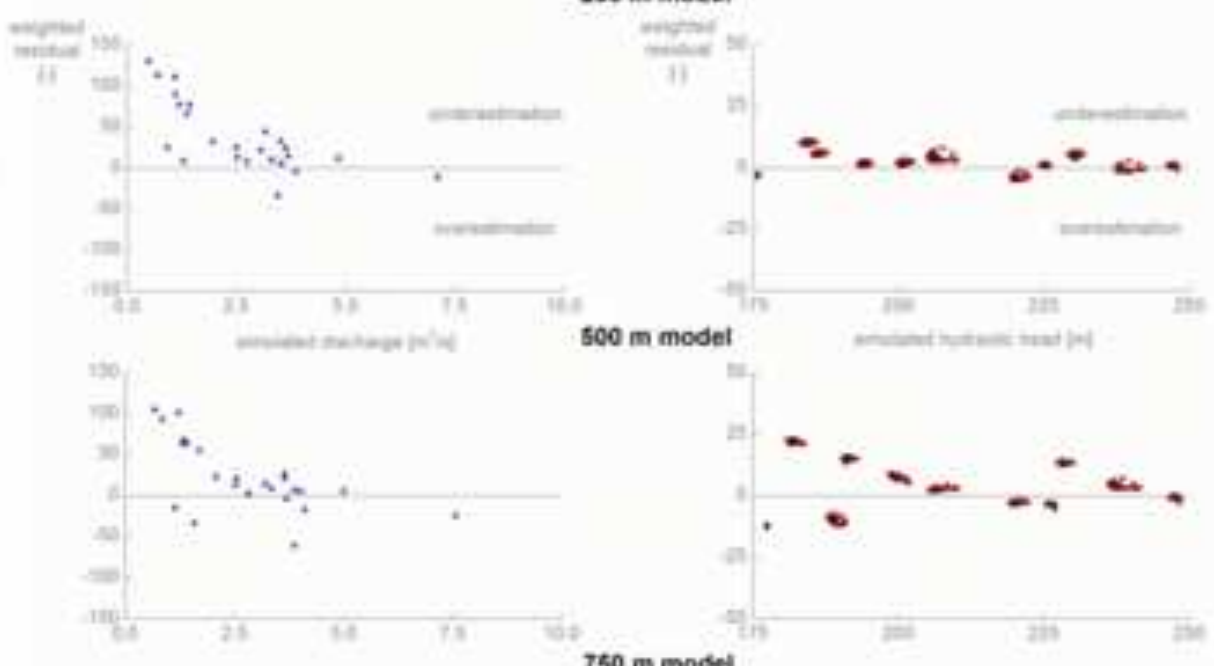

750 m modet
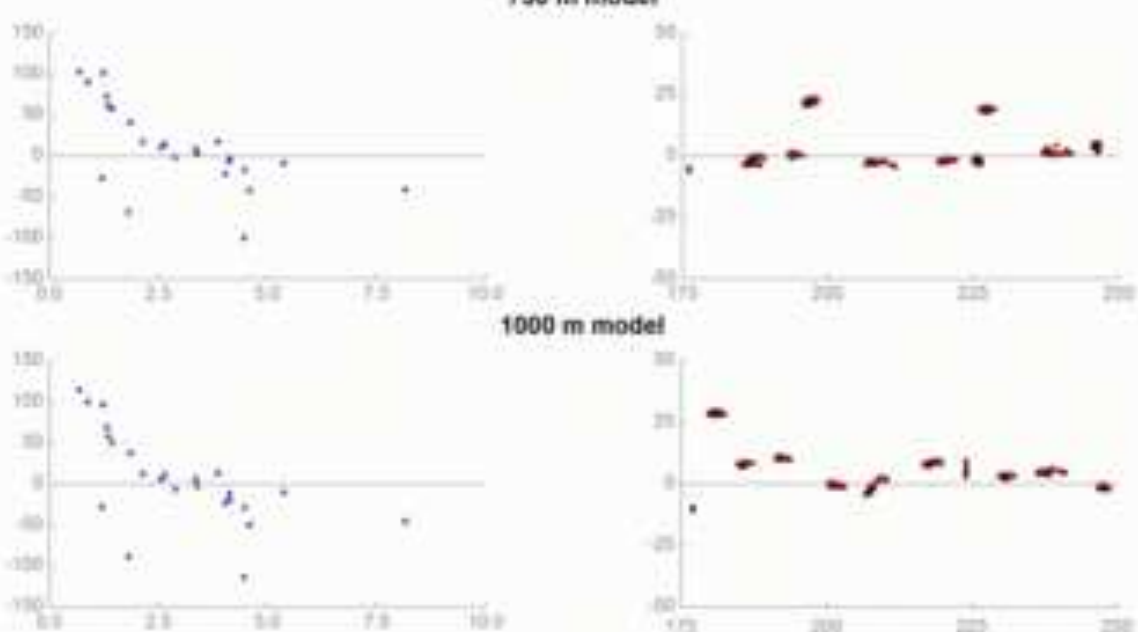

$1000 \mathrm{~m}$ model

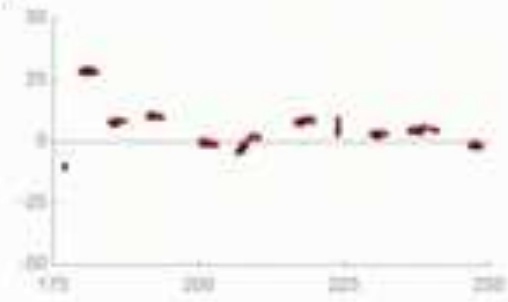




\section{A. beifore es lbretion}

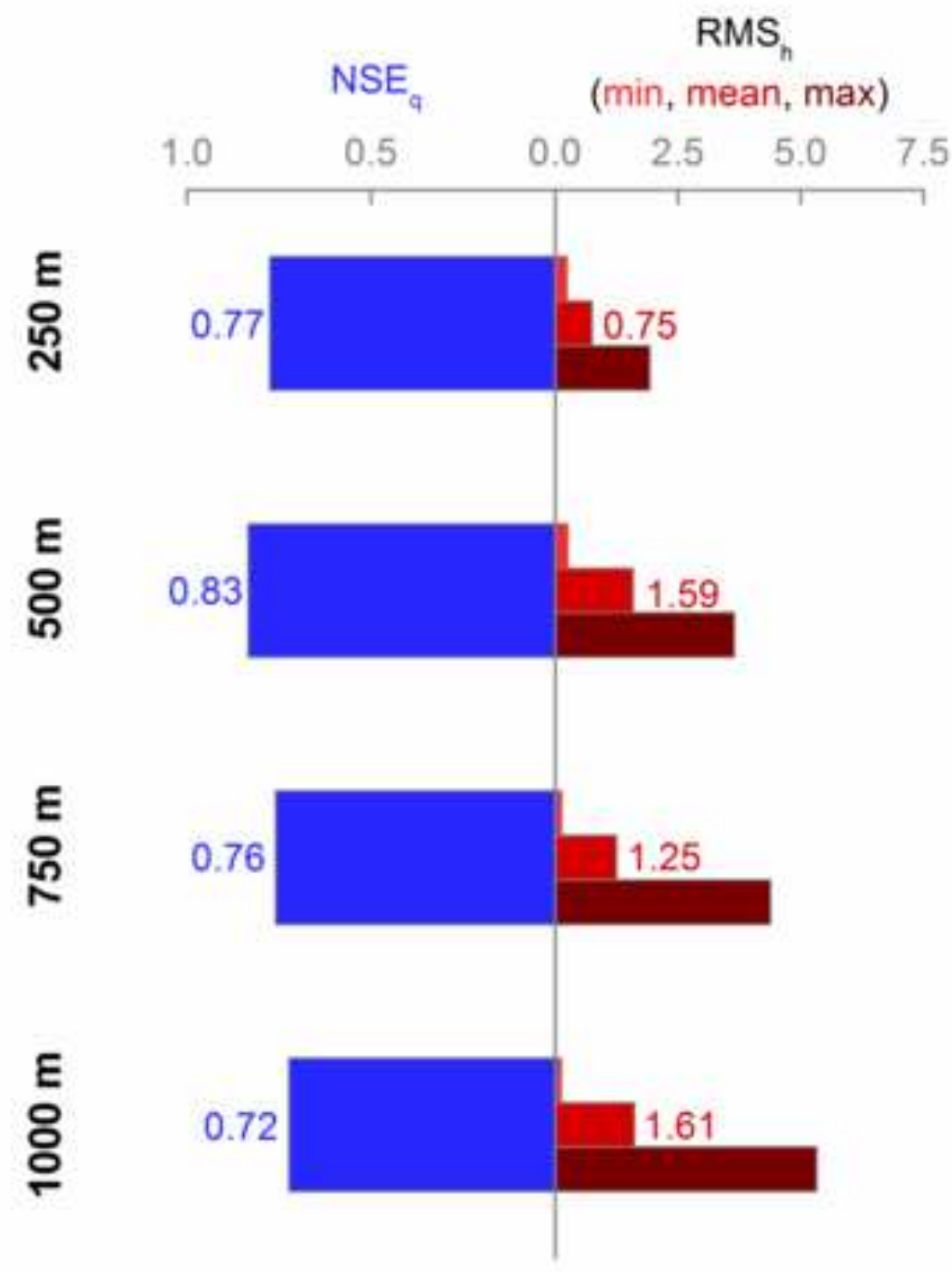

B. efter oe pration

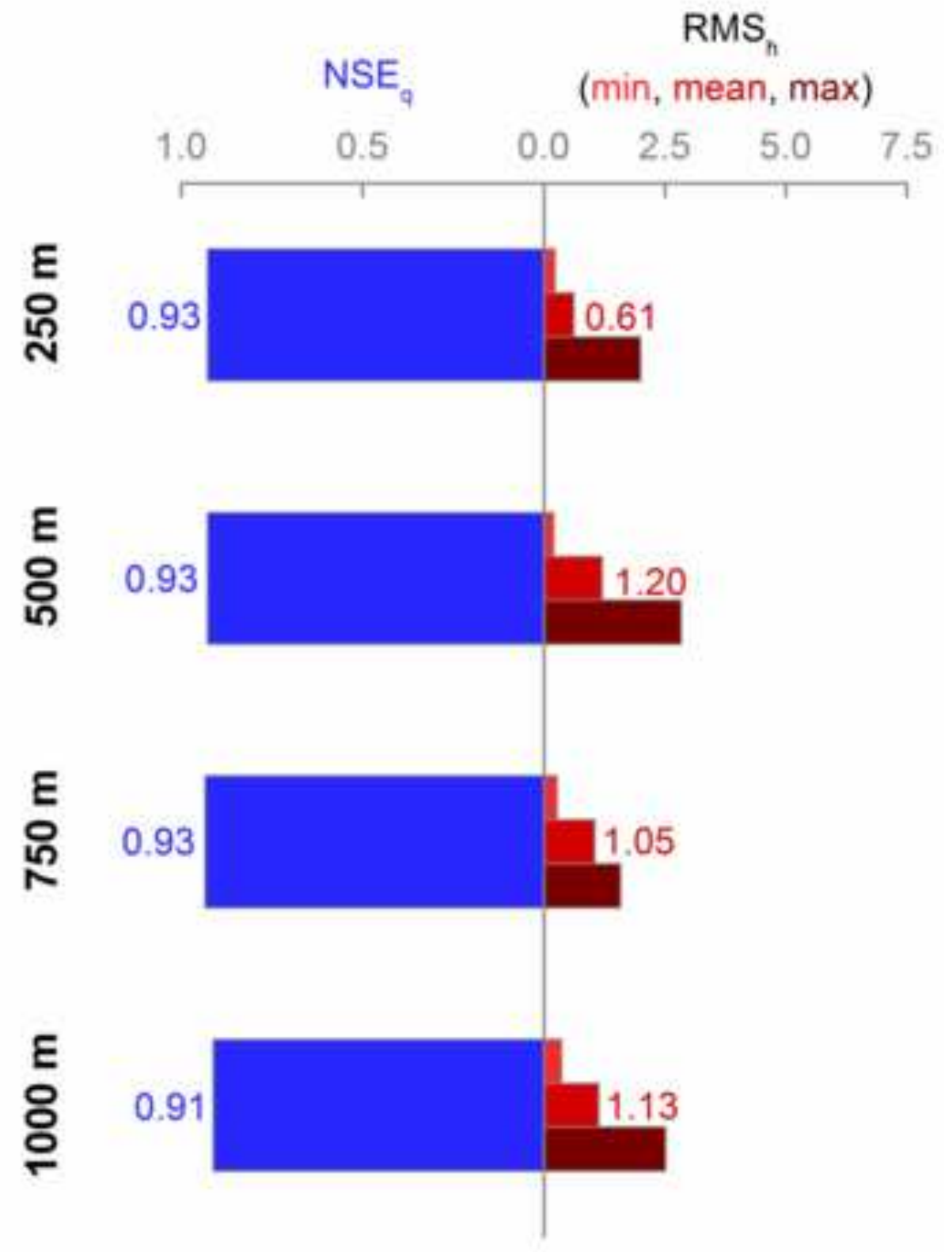


Figure_ 5 here to download high resolution image

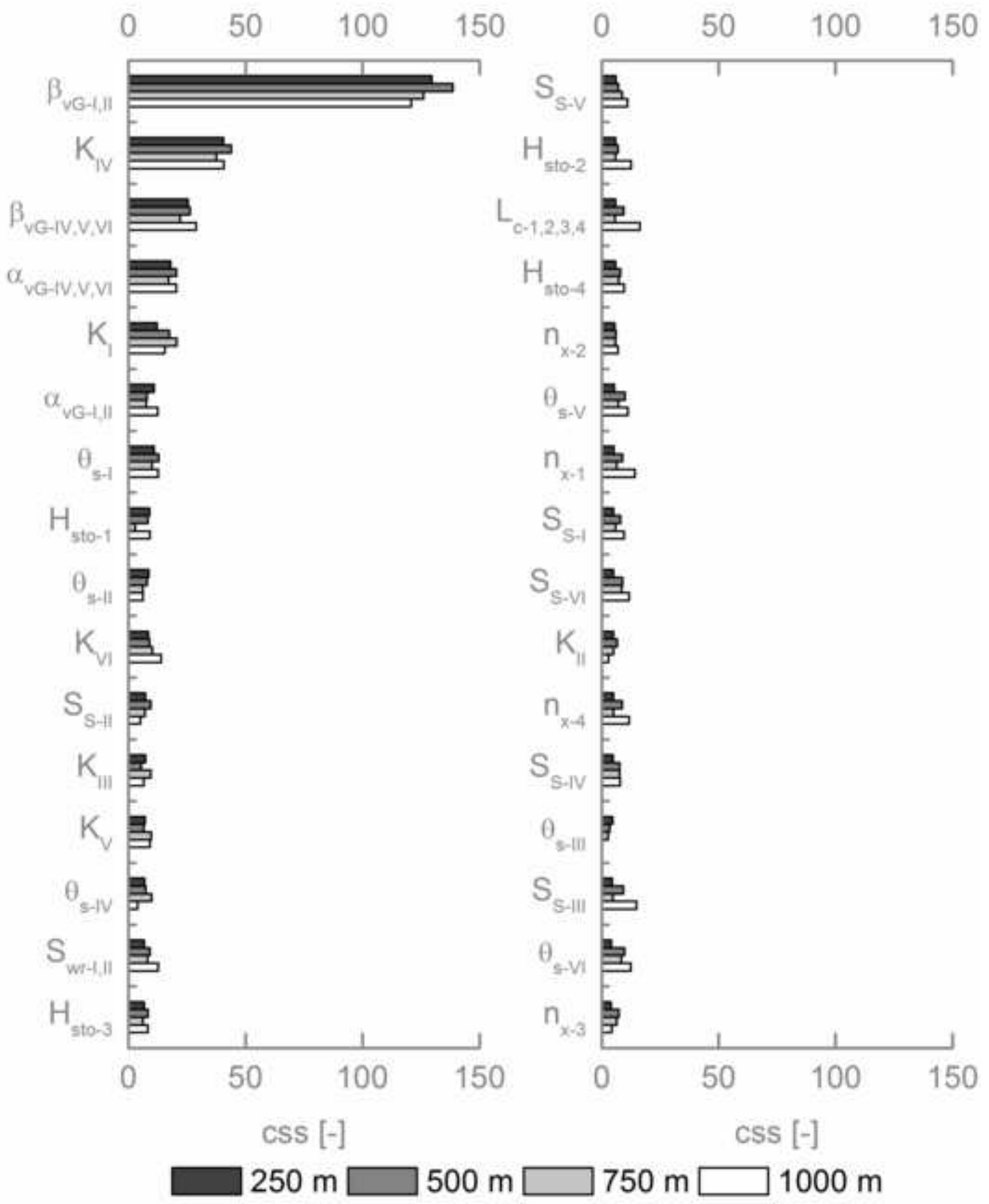


Click here to download high resolution image

A. reference vs simulated values

$250 \mathrm{~m}$ model

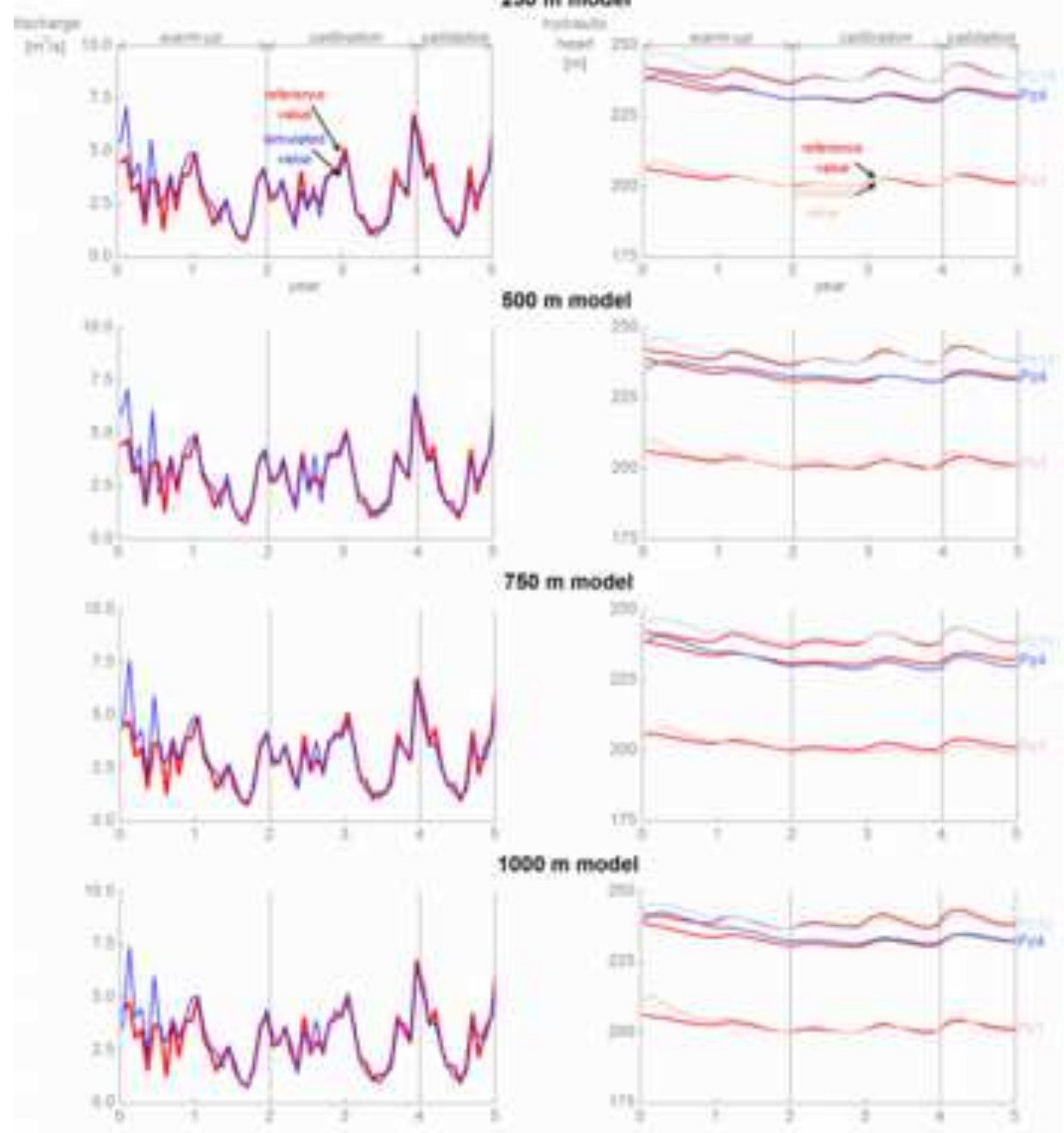

B. simulated values vs weighted residuals

$250 \mathrm{~m}$ model

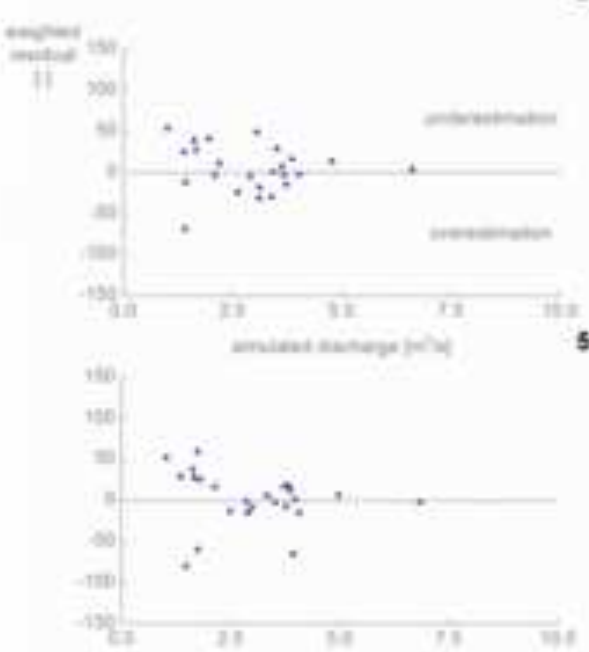

$750 \mathrm{~m}$ modet

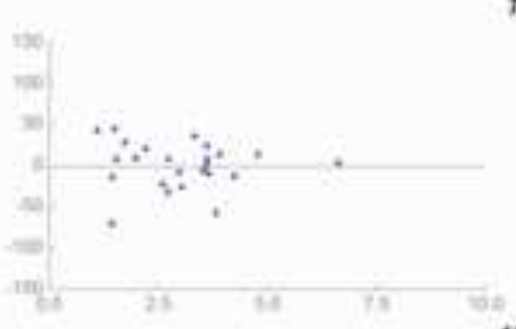

$1000 \mathrm{~m}$ model

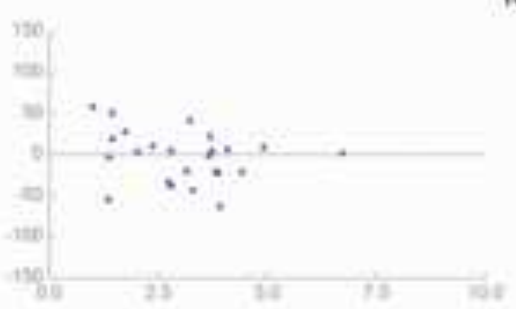

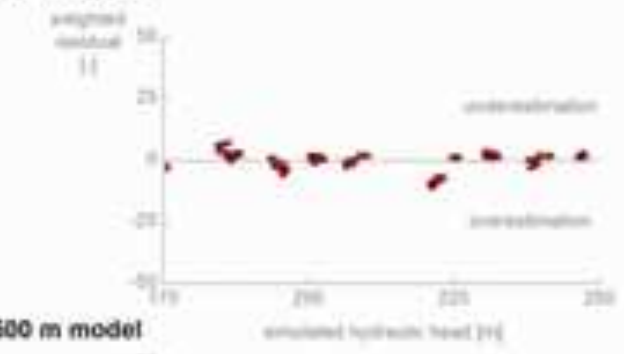
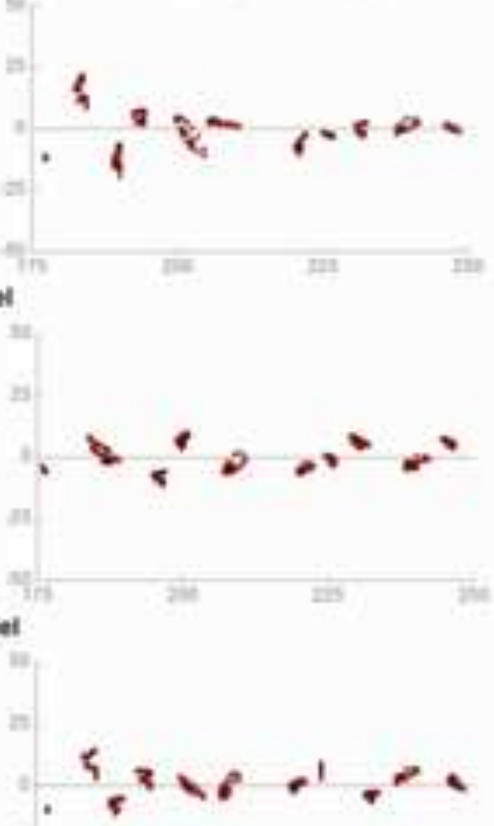
Figure_7

Click here to download high resolution image

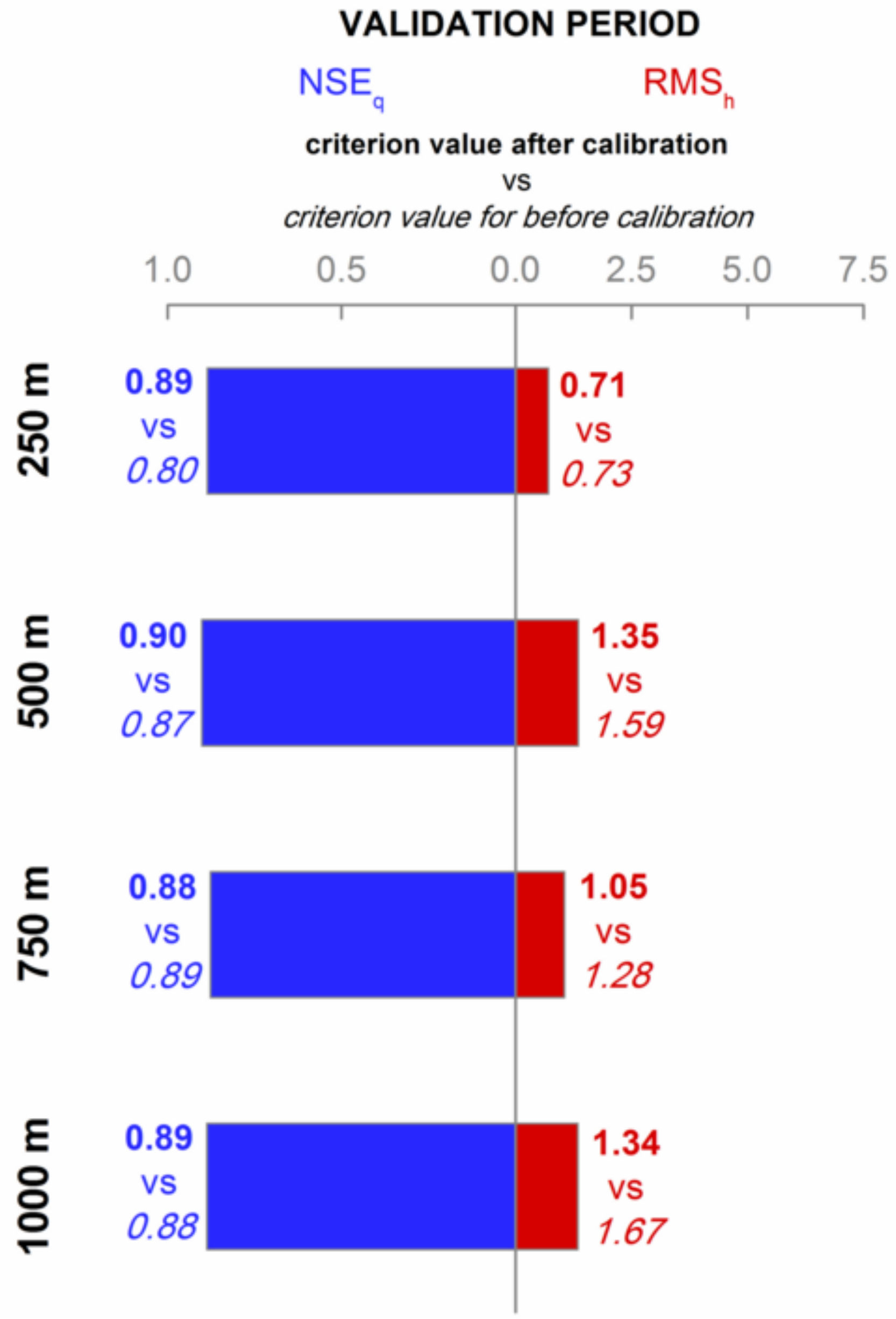


Figure_8
Click here to download high resolution image

\section{$\mathbf{Q}_{\text {outlet }}$}
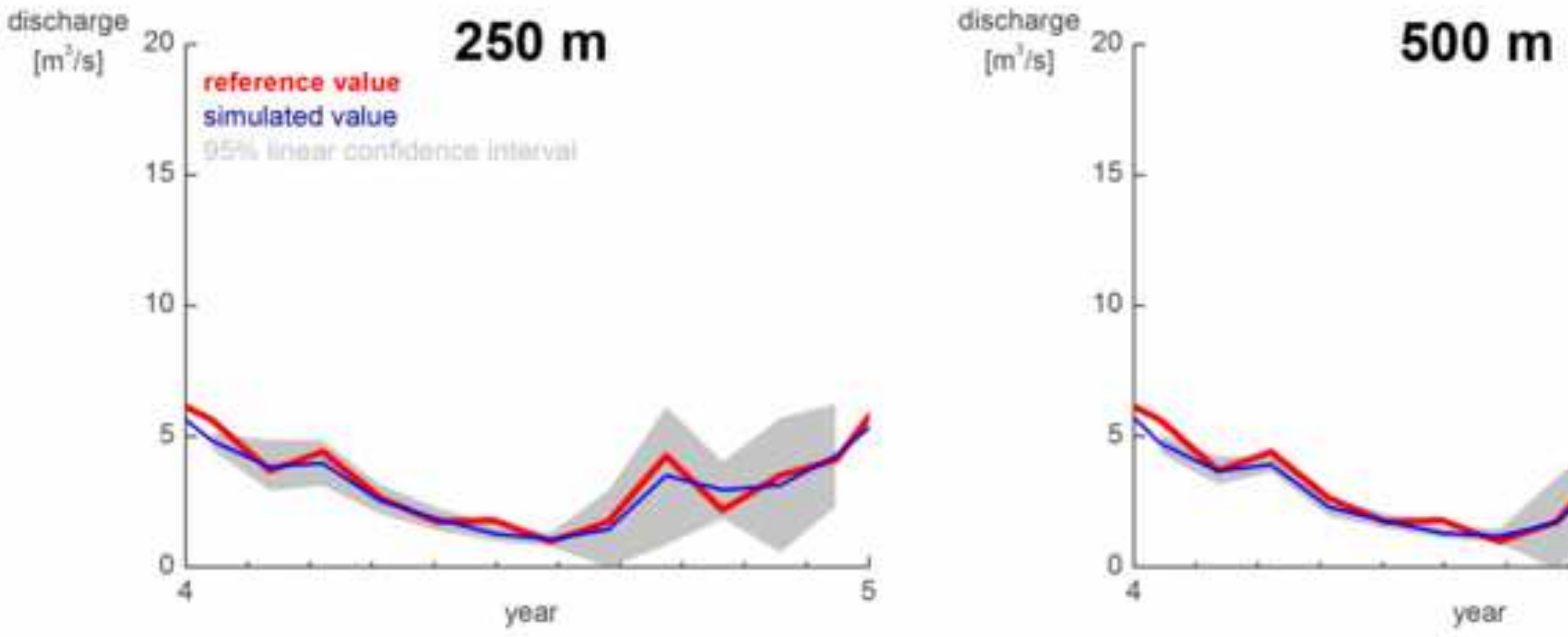

discharge $\left[\mathrm{m}^{3} / \mathrm{s}\right]$

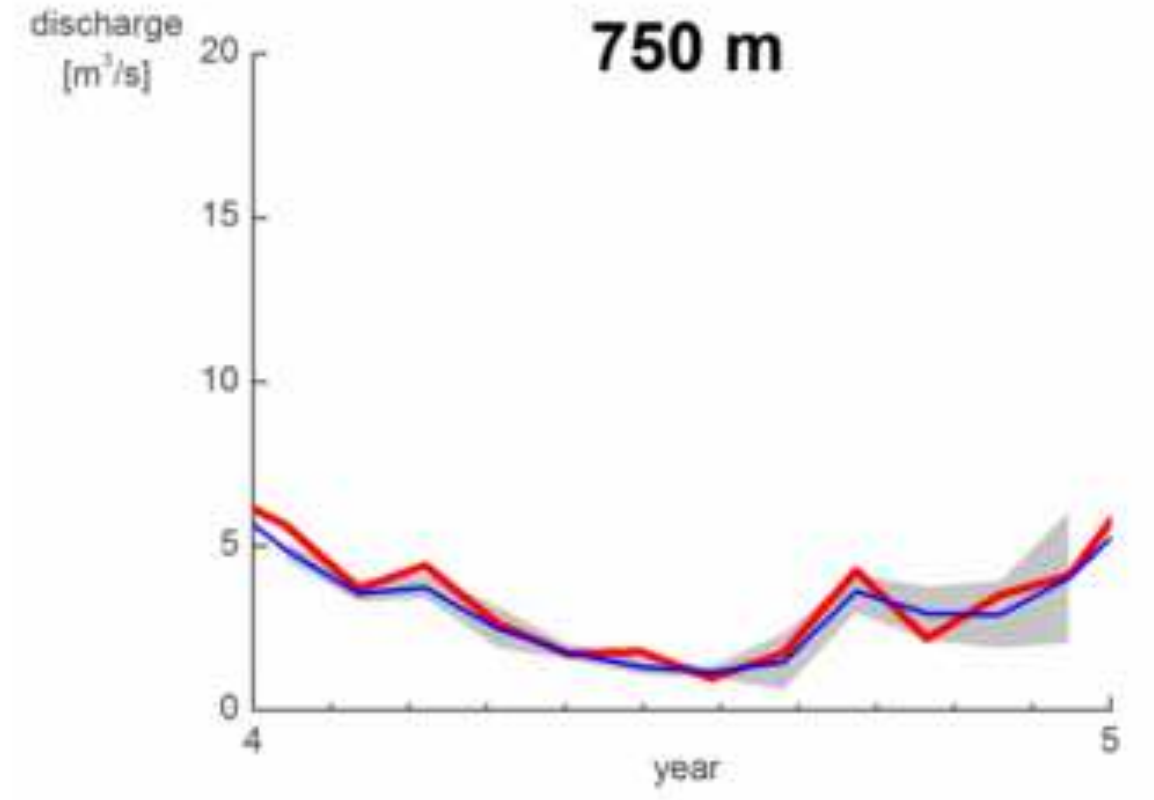

discharge $\left[\mathrm{m}^{3} / \mathrm{s}\right.$ ]
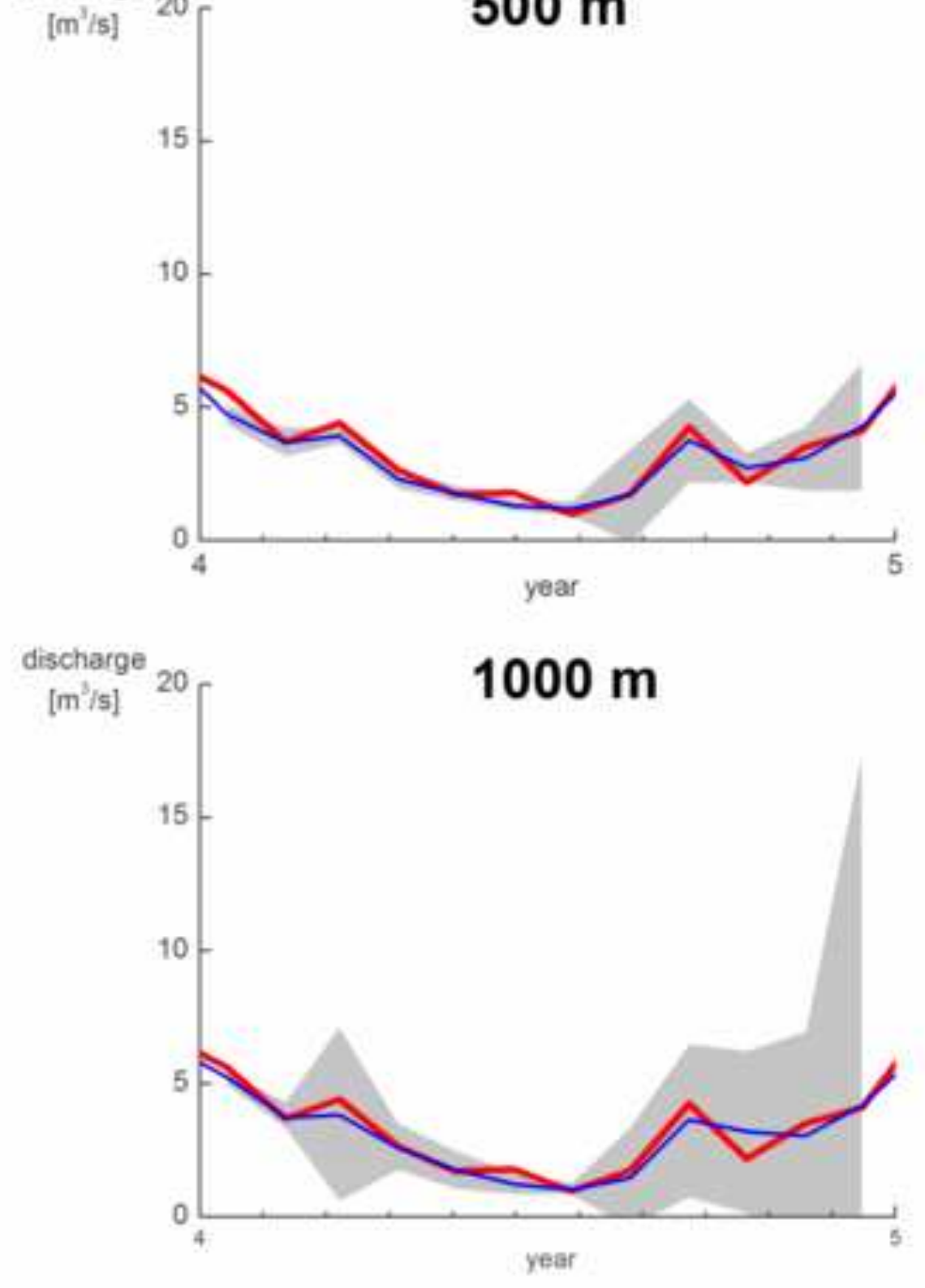
Figure_g
Click here to download high resolution image
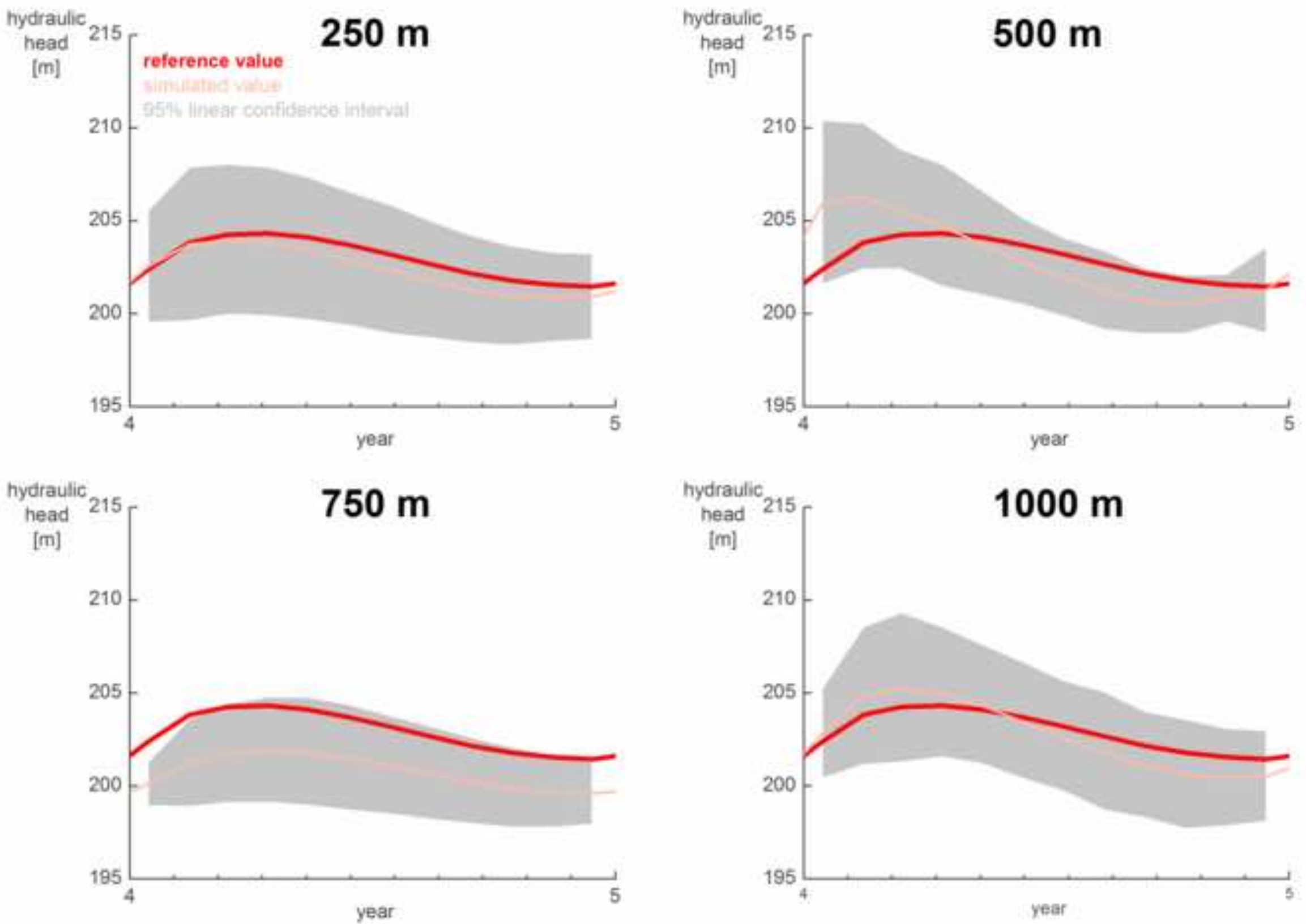
Click here to download high resolution image

\section{Pz4}
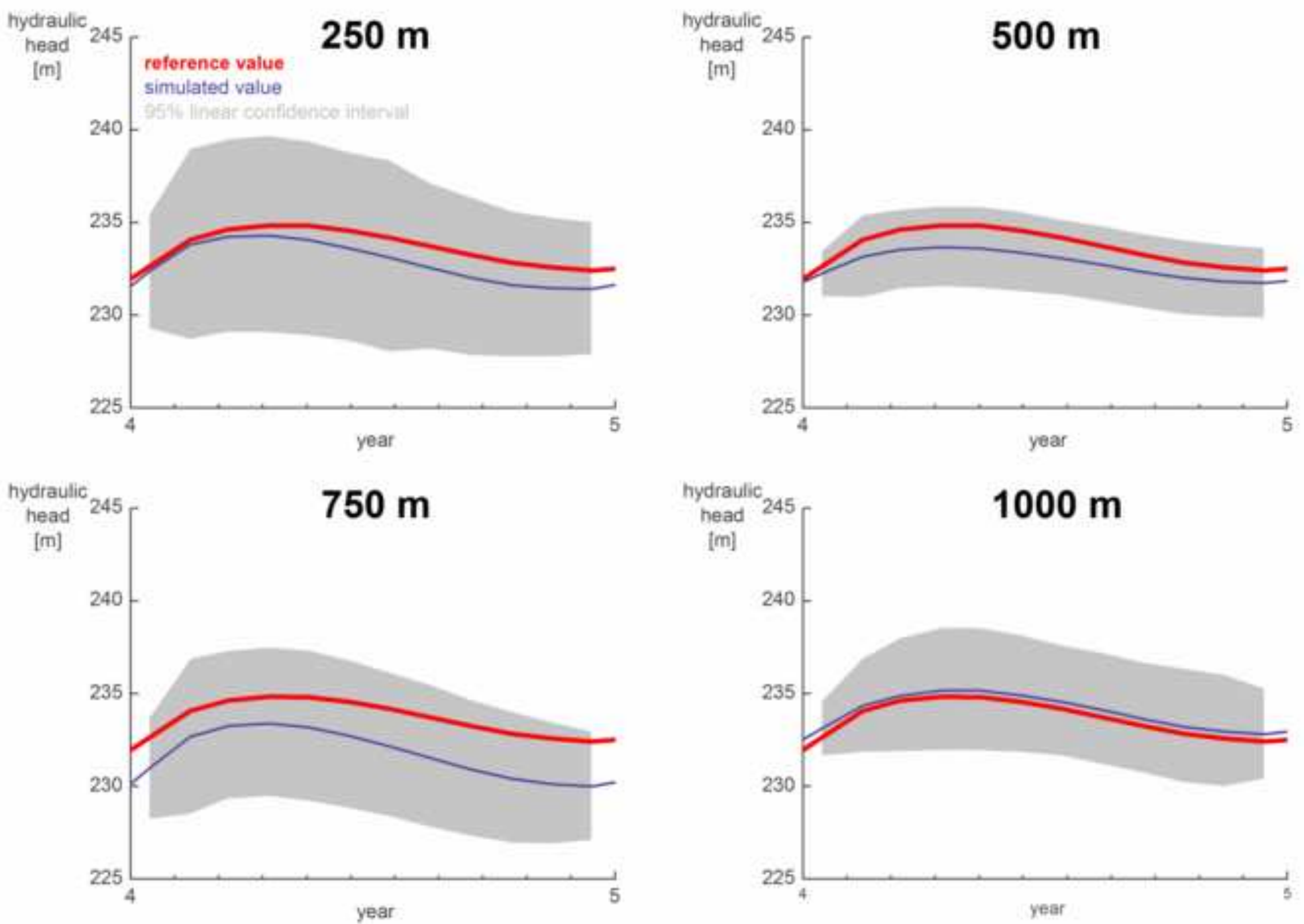
Click here to download high resolution image
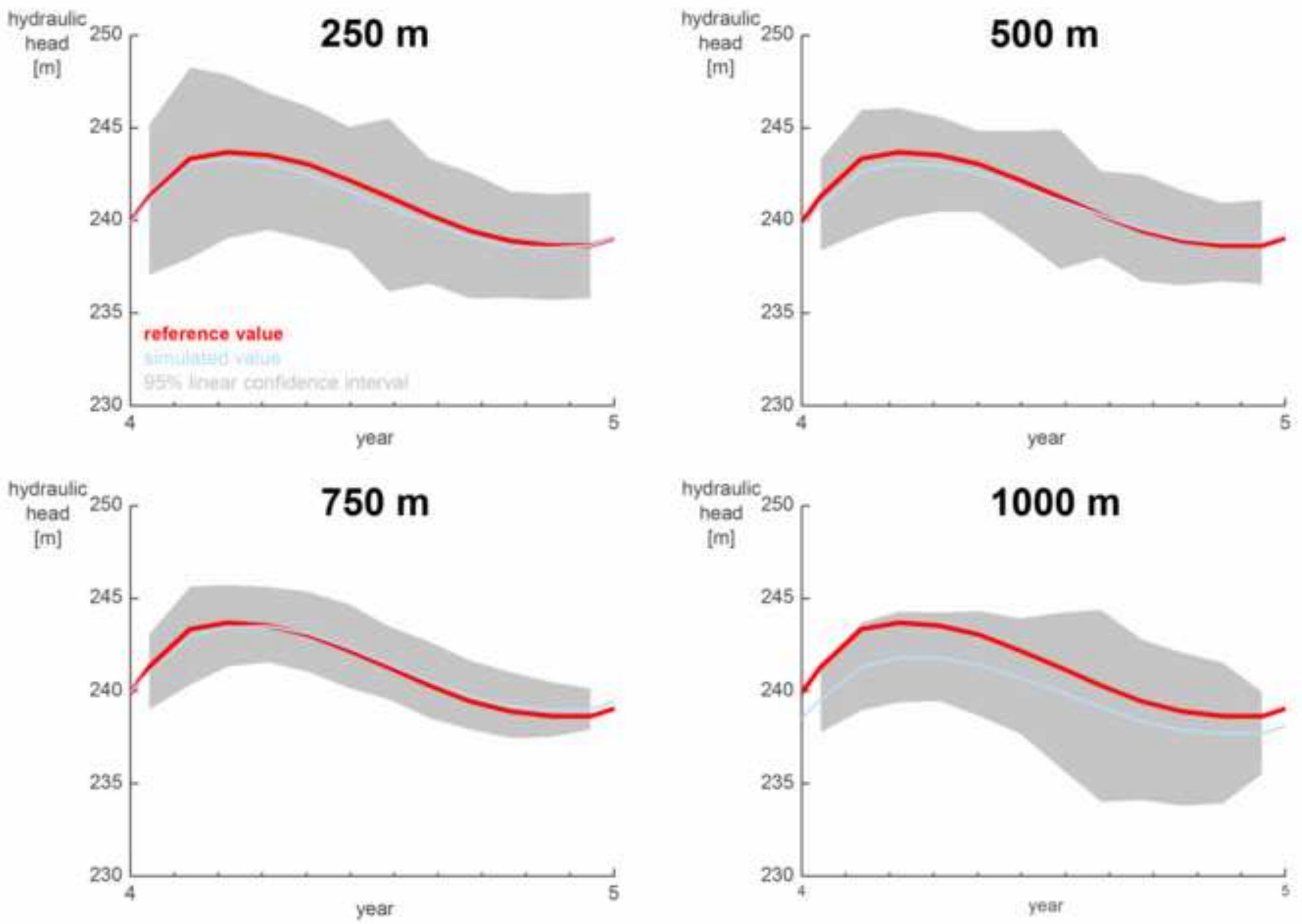
Table

Click here to download Table: Tables.docx

Table 1

\begin{tabular}{lccc} 
& & & \\
& Table 1 & & \\
\cline { 2 - 4 } & Number of nodes & Number of elements & Execution time \\
\hline $\mathbf{2 5 0} \mathbf{m}$ & 61,884 & 107,536 & $6.08 \mathrm{~h}$ \\
$\mathbf{5 0 0} \mathbf{m}$ & 16,200 & 27,544 & $0.71 \mathrm{~h}$ \\
$\mathbf{7 5 0} \mathbf{~}$ & 7,245 & 12,040 & $0.20 \mathrm{~h}$ \\
$\mathbf{1 0 0 0} \mathbf{m}$ & 4,302 & 7,016 & $0.13 \mathrm{~h}$ \\
\hline
\end{tabular}


Table 2

\begin{tabular}{ccccc} 
& $\mathbf{2 5 0} \mathbf{~}$ & $\mathbf{5 0 0 ~} \mathbf{~}$ & $\mathbf{7 5 0} \mathbf{~}$ & $\mathbf{1 0 0 0 ~} \mathbf{~}$ \\
\hline [-] & 0.77 & 0.83 & 0.76 & 0.72 \\
Gupta's 1 $^{\text {st }}$ term [-] & 2.26 & 2.33 & 2.53 & 2.59 \\
Gupta's 2 $^{\text {nd }}$ term [-] & 1.37 & 1.47 & 1.77 & 1.87 \\
Gupta's 3 $^{\text {rd }}$ term [-] & 0.11 & 0.03 & 0.00 & 0.00 \\
[\%] & -14.32 & -7.00 & -1.32 & 1.23 \\
[\%] & -8.65 & -2.01 & 8.27 & 11.66 \\
[\%] & 5.04 & 11.82 & 20.27 & 21.83 \\
\hline
\end{tabular}


Table 3

\begin{tabular}{|c|c|c|c|}
\hline & \multicolumn{3}{|c|}{$250 \mathrm{~m}$} \\
\hline & $\min$ & mean & $\max$ \\
\hline [\%] & -1.03 & -0.17 & 0.50 \\
\hline [\%] & -91.67 & -9.40 & 24.39 \\
\hline \multirow[t]{3}{*}{ [\%] } & -89.96 & -17.69 & 3.66 \\
\hline & \multicolumn{3}{|c|}{$500 \mathrm{~m}$} \\
\hline & $\min$ & mean & $\max$ \\
\hline [\%] & -1.96 & -0.15 & 1.18 \\
\hline [\%] & -91.67 & -4.22 & 51.35 \\
\hline \multirow[t]{3}{*}{ [\%] } & -89.96 & -12.62 & 24.70 \\
\hline & \multicolumn{3}{|c|}{$750 \mathrm{~m}$} \\
\hline & $\min$ & mean & $\max$ \\
\hline [\%] & -2.18 & -0.36 & 0.49 \\
\hline [\%] & -91.67 & -12.46 & 19.51 \\
\hline \multirow[t]{3}{*}{ [\%] } & -78.26 & -19.83 & 2.76 \\
\hline & \multicolumn{3}{|c|}{$1000 \mathrm{~m}$} \\
\hline & $\min$ & mean & Max \\
\hline [\%] & -2.86 & -0.62 & 0.96 \\
\hline [\%] & -98.04 & -21.46 & 21.62 \\
\hline [\%] & -94.41 & -24.97 & 10.98 \\
\hline
\end{tabular}


Table 4

$250 \mathrm{~m} \quad 500 \mathrm{~m} \quad 750 \mathrm{~m} \quad 1000 \mathrm{~m}$

\begin{tabular}{ccccc}
\hline [-] & 0.93 & 0.93 & 0.93 & 0.91 \\
Gupta's $^{\text {st }}$ term [-] & 1.87 & 2.01 & 1.87 & 1.91 \\
Gupta's 2 $^{\text {nd }}$ term [-] & 0.94 & 1.08 & 0.94 & 1.00 \\
Gupta's 3 $^{\text {rd }}$ term [-] & 0.01 & 0.00 & 0.00 & 0.00 \\
[\%] & -3.44 & -0.28 & -1.82 & 0.26 \\
[\%] & -4.81 & -2.49 & 0.28 & 4.62 \\
[\%] & -2.44 & 1.71 & -2.42 & -4.25 \\
\hline
\end{tabular}


Table 5

\begin{tabular}{|c|c|c|c|}
\hline & \multirow{2}{*}{\multicolumn{3}{|c|}{$250 \mathrm{~m}$}} \\
\hline & & & \\
\hline & $\min$ & mean & $\max$ \\
\hline [\%] & -0.48 & 0.06 & 0.90 \\
\hline [\%] & -95.24 & -15.08 & 49.62 \\
\hline \multirow[t]{3}{*}{ [\%] } & -88.46 & -7.57 & 38.43 \\
\hline & \multicolumn{3}{|c|}{$500 \mathrm{~m}$} \\
\hline & $\min$ & mean & $\max$ \\
\hline [\%] & -1.09 & 0.31 & 1.47 \\
\hline [\%] & -85.71 & -7.83 & 98.20 \\
\hline \multirow[t]{3}{*}{ [\%] } & -80.77 & -3.78 & 93.93 \\
\hline & \multicolumn{3}{|c|}{$750 \mathrm{~m}$} \\
\hline & $\min$ & mean & $\max$ \\
\hline [\%] & -0.96 & -0.04 & 0.79 \\
\hline [\%] & -36.11 & 5.14 & 52.74 \\
\hline \multirow[t]{3}{*}{ [\%] } & -28.45 & 18.92 & 96.15 \\
\hline & \multicolumn{3}{|c|}{$1000 \mathrm{~m}$} \\
\hline & $\min$ & mean & $\max$ \\
\hline [\%] & -1.72 & -0.16 & 0.93 \\
\hline [\%] & -98.04 & -21.40 & 61.26 \\
\hline [\%] & -96.50 & -16.89 & 63.16 \\
\hline
\end{tabular}


Table 6

\begin{tabular}{lccccc}
\cline { 2 - 6 } & reference model & $\mathbf{2 5 0} \mathbf{~}$ & $\mathbf{5 0 0 ~} \mathbf{~}$ & $\mathbf{7 5 0 ~} \mathbf{~}$ & $\mathbf{1 0 0 0 ~} \mathbf{~}$ \\
\hline $\mathrm{K}_{\mathrm{I}}[\mathbf{m} / \mathrm{s}]$ & $5.00 \times 10^{-7}$ & $1.00 \times 10^{-6}$ & $1.66 \times 10^{-6}$ & $1.92 \times 10^{-7}$ & $7.38 \times 10^{-7}$ \\
$\mathrm{~K}_{\mathrm{IV}}[\mathrm{m} / \mathrm{s}]$ & $1.00 \times 10^{-4}$ & $9.91 \times 10^{-5}$ & $1.04 \times 10^{-4}$ & $9.75 \times 10^{-5}$ & $8.05 \times 10^{-5}$ \\
$\boldsymbol{\alpha}_{\mathrm{vG}-\mathrm{IV}, \mathrm{V}, \mathrm{VI}}[\mathbf{1} / \mathrm{m}]$ & $3.65 \times 10^{-2}$ & $4.98 \times 10^{-2}$ & $4.56 \times 10^{-2}$ & $5.04 \times 10^{-2}$ & $3.04 \times 10^{-2}$ \\
$\boldsymbol{\beta}_{\mathrm{vG}-\mathrm{III}}[-]$ & 1.45 & 1.47 & 1.32 & 1.53 & 1.39 \\
$\boldsymbol{\beta}_{\mathrm{vG}-\mathrm{IV}, \mathrm{V}, \mathrm{VI}}[-]$ & 1.83 & 2.21 & 2.42 & 2.18 & 1.77 \\
\hline
\end{tabular}

